\title{
Adult-mediated connectivity and spatial population structure of sardine in the Bay of Biscay and Iberian coast
}

\author{
Silva Alexandra ${ }^{1,2,{ }^{*} \text {, Garrido Susana }}{ }^{1,2}$, Ibaibarriaga Leire ${ }^{3}$, Pawlowski Lionel ${ }^{4}$, Riveiro Isabel ${ }^{5}$, \\ Marques Vitor ${ }^{1}$, Ramos Fernando ${ }^{6}$, Duhamel Erwan ${ }^{4}$, Iglesias Magdalena ${ }^{7}$, Bryère Philippe ${ }^{8}$, \\ Mangin Antoine ${ }^{8}$, Citores Leire ${ }^{3}$, Carrera Pablo ${ }^{5}$, Uriarte Andres ${ }^{9}$
}

${ }^{1}$ Instituto Português do Mar e da Atmosfera - IPMA, Av. Brasília, 6, 1449-006 Lisboa, Portugal

${ }^{2}$ MARE - Marine and Environmental Sciences Centre Faculdade de Ciências, Universidade de Lisboa, Campo Grande, 1749-016 Lisbon, Portugal

${ }^{3}$ AZTI, Txatxarramendi Ugartea z/g, E-48395 Sukarrieta - Bizkaia, Spain

${ }_{5}^{4}$ IFREMER, Fishery Science and Technology unit, 8 rue François Toullec, 56100 Lorient, France

${ }^{5}$ Centro Oceanográfico de Vigo, Instituto Español de Oceanografía, Subida a Radio Faro 50, 36390-

Vigo, Spain

${ }^{6}$ Centro Oceanográfico de Cádiz, Instituto Español de Oceanografía, Puerto Pesquero, Muelle de Levante, s/n, 11006 Cádiz, Spain

${ }^{7}$ Centro Oceanográfico de Baleares, Instituto Español de Oceanografía, Muelle de Poniente, s/n, Apartado de Correos 291, 07015 Palma, Spain

${ }^{8}$ ARGANS-FR, 260 Route du Pin Montard, BP 234, 06904 Sophia-Antipolis, France

${ }^{9}$ AZTI, Herrera Kaia, Portualdea z/g. E-20110, Pasaia-Bizkaia, Spain

* Corresponding author : Alexandra Silva, email address : asilva@ipma.pt

\begin{abstract}
:
This work investigated adult-mediated connectivity and spatial population structure of sardine in the European Atlantic waters. The spatial and temporal progress of cohorts was modelled using abundance-at-age survey data by area in the period 2000 to 2016, covering the region from the northern Bay of Biscay to the eastern Gulf of Cadiz. A novel methodology was used to calculate indices of cohort movement between areas. Movement was relatively low between three large regions, the Bay of Biscay, the northern Spanish and Portuguese waters and the Gulf of Cadiz, each hosting a recruitment hotspot. On the other hand, one half of the sardines recruited in North Portugal and a quarter of those recruited in Southwest Portugal moved to northern Spanish waters and South Portugal, sustaining local populations and fisheries. Movement was mainly driven by recruitment strength and, in a less extent, by food availability during fall. The connectivity and dynamic patterns suggest a metapopulation with three weakly connected populations and density-dependent source-sink movement within the northern Spanish and Portuguese waters population. While the weak connectivity does not invalidate the management boundary between the Bay of Biscay and the Iberian Peninsula, the Gulf of Cadiz may be treated as a separate stock. Multi-area/metapopulation assessment approaches should be applied to account for complex population structure, the higher risks of depleting source areas and/or less productive populations.
\end{abstract}


Keywords: Metapopulation, Source-sink dynamics, Adult-mediated connectivity, Cohort dispersal, Small pelagic fishes, Stock identity, Fisheries management 


\section{Introduction}

Marine fishes are often structured in multiple subpopulations connected by exchange of early life stages, juveniles and adults (Secor 2015). Subpopulations are likely to have different life history traits and demographic characteristics reflecting genetic diversity and phenotypic plasticity, and may respond differently to environmental variability and fishing exploitation. Spatial population structure and connectivity influence population dynamics, therefore they must be taken into account in stock assessment and fisheries management (Cadrin et al., 2014; Goethel and Berger, 2017; Kerr et al., 2016; Pita et al., 2016).

Despite evidence of complex population structure and mixing within and between stocks, assessment and fisheries management advice still assume closed stocks for the majority of cases (Kerr et al., 2016). The spatial structure needs to be considered when addressing management issues otherwise the sustainability of resources and fishing activity might be impaired. If the closed stock assumption is violated, management of a mixed stock complex can potentially lead to overfishing of the less productive populations and under-fish the most productive populations (Kerr et al., 2010). Management of a portion of a stock may also lead to unsustainable exploitation as the stock distribution changes over time and there are spatial differences in demography and population dynamics.

To incorporate complex spatial population structure into assessment and management it is necessary to have knowledge of the connectivity between sub-populations, namely on the directions and rates of dispersal/transport and migration. Connectivity may be established at various life stages. Larval dispersal/transport has been given far more attention than juvenile or adult dispersal in studies of spatial population structure (Lipcius et al., 2008) but recent studies 
argue that adult-mediated connectivity is a widespread form of connectivity and plays an important role in the structure and dynamics of fish populations (Archambault et al., 2016; Frisk et al., 2014). Conceptual models of population structure based on larval-mediated connectivity (Lipcius et al., 2008) have been transposed to cases of adult-mediated connectivity (Secor et al., 2009).

Tagging, genetics, otolith microchemistry and parasite analyses are some of the approaches that may be used to estimate movement rates between sub-populations (Kerr and Campana, 2013; MacKenzie and Abaunza, 2013; Schwarz, 2013). Demography also provides information on the spatial structure of populations and may be used to derive qualitative indices of movement between sub-populations (Peoples and Frimpong, 2012). For example, Murta et al. (2008) described horse mackerel (Trachurus trachurus) ontogenetic migrations in the Iberian waters based on the geographic variation of the age composition of cohorts. This approach is particularly valuable to study metapopulations, a type of spatial structure and dynamics that has been frequently proposed for small pelagic fish (e.g. North Sea herring, Clupea harengus: McQuinn, 1997; Ruzzante et al., 2006: blue whiting, Micromesistius poutassou: Was et al., 2008; sprat, Sprattus sprattus: Limborg et al., 2009). A metapopulation is a regional group of local subpopulations, each of which is generally self-sustained, but connected through dispersal of individuals and interbreeding (Kritzer and Sale, 2004).

Connectivity among subpopulations in a metapopulation may be driven by densitydependent or density-independent dispersal and may be unidirectional or bidirectional (Secor et al., 2009; Shepherd and Litvak, 2004). The type and degree of connectivity influence the similarity of life history and demographic traits, the stability and productivity of the various subpopulations and of the metapopulation (Cadrin and Secor, 2009; Kerr et al., 2010). When 
subpopulations differ in productivity, movement tends to be driven by population abundance and to run from the more productive to the less productive subpopulation, known as source-sink dynamics (Goethel and Berger, 2017). Source populations tend to have higher proportions of juveniles than adults whereas the opposite is seen in sink populations; the differences between age distributions may be used to assess movement between the two (Peoples and Frimpong, 2012). Differences in age structure are likely to be amplified for species that undergo ontogenetic changes in habitat from juvenile stages (in restricted nursery grounds) to subadult and adult stages (more widespread) (Vasconcelos et al., 2014).

Sardine (Sardina pilchardus, Walbaum) is a valuable fishing resource in Europe with annual landings from the Bay of Biscay and Iberian Peninsula above 100,000 t since the late 1970s (Silva et al., 2015). Assessment and management assume three stocks in European Atlantic waters: the Bay of Biscay (BoB) stock, the Iberian Peninsula (IP) stock and the southern Celtic Seas-English Channel (CS) stock, recently considered to be separate from the BoB stock (ICES, 2017a). Over the last 15 years, the IP stock decreased severely due to prolonged low recruitment and high catch levels, with serious social and economic impact on the Portuguese and Spanish purse seine fishery. The BoB stock is healthy with recent increases in its fishery yields (since 2012), partly as a result of restricted fishing for the IP stock. Knowledge of the CS stock is limited due to the lack of monitoring; available data restricted to landings and acoustic surveys covering part of the stock in recent years, do not raise concern about fishing levels.

The existence of sardine subpopulations in the Bay of Biscay and Iberian Peninsula has been suggested by geographical differences in biological traits and demographic rates (e.g. morphometrics, growth, recruitment) although the boundaries and connectivity between putative subpopulations are unclear (ICES, 2016 and references therein). Regional age structures typical 
of source-sink dynamics have been suggested (Silva et al., 2009). The contrasting abundance trends between the BoB and the IP stocks provided an opportunity to improve knowledge on connectivity between areas and how it is affected by abundance/density and environmental conditions. Within the region there are contrasting oceanographic and environmental features, that may be responsible not only for the observed differences between subpopulations but also for the movement of sardines between areas. Sardine larvae growth and survival were shown to be highly dependent on temperature (Garrido et al., 2015), which is probably reflected in the

local variability of recruitment success. On the other hand, sardines are exclusive planktivorous fish, feeding on small zoo- and phytoplankton prey (Garrido et al., 2015), therefore, sardine population dynamics are probably related to plankton productivity.

This study aims to investigate the magnitude of movement of adult sardines within the region from the northern Bay of Biscay to the eastern Gulf of Cadiz, to identify the main connectivity paths between areas, and identify drivers of movement. The results will improve knowledge of the spatial structure and dynamics of populations, assist the re-evaluation of stock boundaries and provide information to develop multi-area stock assessment models and test spatial management strategies for the sardine fisheries.

\section{Material and Methods}

\subsection{Data}

Total biomass (thousand t), total abundance and abundance-at-age (billions of individuals), and distribution area $\left(\mathrm{nm}^{2}\right)$ were obtained from annual acoustic surveys carried out by France (PELGAS, since 2000), Spain (PELACUS, March/April since 1996) and Portugal 
(PELAGO, March/May, since 1996 with gaps in 2004 and 2012) that covered the whole study area. Mean fish density was calculated as total abundance/distribution area (billions of individuals $/ \mathrm{nm}^{2}$ ). Details on the methodology of the surveys are described in Massé et al. (2017). French surveys spanned the areas from Brittany $\left(48^{\circ} \mathrm{N}\right)$ to the French-Spanish border in the Bay of Biscay, Spanish surveys spanned the areas from that border to the Spanish-Portuguese border in northwest Iberia, and Portuguese surveys spanned the Portuguese waters and the Gulf of Cadiz (Fig. 1). All surveys covered continental shelf waters, Spanish and French surveys extended the areal coverage to the upper slope ( $500 \mathrm{~m}$ depth). Acoustic surveys were coordinated under the framework of the International Council for the Exploration of the Sea (ICES) (ICES 1998, 2006a). The French survey was used to calibrate the BoB stock assessment model and the Spanish and Portuguese surveys were combined in a single abundance-at-age index to calibrate the IP stock assessment model (ICES, 2017b).

Catch biomass (thousand t) and catch-at-age (millions of individuals) data by ICES subdivision from 2000 (2002 in the Bay of Biscay) to 2015 were compiled from annual reports of ICES working groups for sardine stock assessment (e.g. ICES, 2017a). Age groups ranged from 0 or 1 to 7 years in catch and survey data, respectively.

Satellite-derived data used in this study were seasonal averages (winter, spring, summer and fall) of Sea Surface Temperature (SST), from daily PATHFINDER V5.2 products (Casey et al., 2010) and seasonal averages of Chlorophyll-a concentration (Chl-a) from GlobColour products (all details on input data and algorithms used are described in the GlobColour Product User Guide 2014, http://hermes.acri.fr/, http://www.globcolour.info/CDR_Docs/GlobCOLOUR_PUG.pdf). 
Data on sardine abundance, fisheries and oceanographic conditions were disaggregated in eight areas across the Bay of Biscay and Iberian Peninsula waters (Fig. 1): Bay of Biscay (BISC), Cantabrian Sea (CAN), North Galicia (NGAL), South Galicia (SGAL), North Portugal (NPOR), Southwest Portugal (SWPOR), South Portugal (SPOR) and Gulf of Cadiz (CAD). The areas correspond to the geographic strata used for the estimation of sardine in acoustic surveys and broadly overlap with ICES sub-divisions used to report sardine catch data since 1991. Throughout this work, there was a need to refer to broader geographic regions that encompass several subareas. Therefore, the term "northern Spanish waters/areas" refers to the region including CAN, NGAL and SGAL, "Portuguese areas/waters" refers to the region including NPOR, SWPOR and SPOR, "Galician waters/areas”, refers to NGAL and SGAL, "western Iberia" refers to SGAL, NPOR and SWPOR, "western Portugal" to the latter two areas and "southern Iberia" refers to SPOR and CAD.

\subsection{Model for regional-temporal distribution of cohorts}

Sardine abundance data are zero-inflated with zero values being possibly a mixture of false zeroes (due to poor sampling) and true zeros (real absence from the area), which are impossible to separate. In this case, the recommended approach is to use a two-part model, i.e. to model zero (usually with a binomial model) and non-zero (usually with zero-truncated Poisson or Negative Binomial models) data separately and pool the results thereafter (Zuur et al., 2009).

We used a two-part (hurdle) Generalized Additive Model (GAM) to investigate the variability of sardine abundance in each of the 8 areas by cohort (1999-2015) and age (1-7 
years). The sub-model for sardine presence (pres) assumed a binomial error distribution and a logit-link function and had the form:

$$
\text { pres }=\mathrm{s}(\text { age }, \text { area })+\mathrm{s}(\text { cohort, area }),
$$

where the smooth functions s(.) are thin plate regression splines describing the interaction of age and cohort (continuous variables) with the area (categorical variable), respectively. Due to the pronounced over-dispersion, the sub-model for sardine non-zero abundance-at-age data (count data) assumed a zero-truncated negative binomial (NB) distribution (theta estimated) and a loglink function. Area was used as a continuous variable instead of a categorical variable in modelling count data to allow higher model flexibility, particularly of the cohort:area interaction, which was important to improve the fit of count data but not of presence/absence data. The general form of the count model was:

$$
\text { hcount }=\text { te }(\text { cohort, area, age), }
$$

were the smooth function, te(.) is a tensor product cubic spline describing the three-way interaction between cohort, area and age (all continuous variables). In a strict sense, area is a categorical variable. However, area levels can be ordered in a sensible way, for example, from south to north, in which case the variable may be considered a non-strict ordinal variable (nonstrict because levels represent unequal intervals) denoting an underlying continuous variable such as "distance" to the southern limit of the surveyed area (Winship and Mare, 2014). Area levels were coded numerically from south $(\mathrm{CAD}=1)$ to north $(\mathrm{BISC}=8)$.

Best fit models were selected by backward elimination of variables based on the Akaike Information Criterion (AIC).

Abundance predicted by the two-part model was given by:

$$
\text { abundance }=\text { pres } * \text { count } /\left(1-\mathrm{P}_{0}\right)
$$


with variance:

$$
\operatorname{Var}[\text { abundance }]=\left(\text { pres } /\left(1-\mathrm{P}_{0}\right)\right) *\left(\text { count }^{2}+\operatorname{count}+\left(\text { count }^{2} / \mathrm{k}\right)\right)-(\text { abundance })^{2}
$$

where $\mathrm{k}$ is the dispersion parameter of the $\mathrm{NB}$ count data model and $\mathrm{P}_{0}=\mathrm{k} /(\operatorname{count}+\mathrm{k})^{\wedge} \mathrm{k}$, is the probability of zero expected values by the model.

\subsection{Calculation of cohort flow}

The variation of cohort abundance over time in each area results from the combination of natural mortality, fishing mortality and dispersal/migration. Cohort abundance is expected to decrease over time unless the movement of fish into the area is higher than the total mortality (Supplemental file, Fig.S1). In some areas of the Iberian Peninsula, such as the CAN and NGAL, there is a persistent pattern of increasing cohort abundance up to ages 3-4 years, followed by a decreasing trend, suggesting entry of fish from other areas (Silva et al., 2009). The number of fish that move into (inflow) or out (outflow) of a given area may be calculated if data are available on the abundance of consecutive ages of each cohort and on the catches and natural deaths that occurred between those ages. Acoustic surveys are considered to provide relative indices of abundance. Therefore, for the above reasoning to apply, survey selectivity should be constant over age and time.

To calculate flow indices for each of the areas, the movement of age 0 fish between areas was assumed to be negligible. The abundance of age 1 fish in spring acoustic surveys represented local recruitment. Predicted abundances from the two-part GAM were used because observed survey data were noisy and sparse for some cohorts. In each area, the abundance of each cohort 
was projected forward from age 1 to age 4 applying the inverse of Pope's cohort analysis formula (Pope, 1976):

$$
\mathrm{NP}_{\mathrm{a}+1, \mathrm{y}+1}=\mathrm{N}_{\mathrm{a}, \mathrm{y}} * \exp \left(-\mathrm{M}_{\mathrm{a}}\right)-\mathrm{C}_{\mathrm{a}, \mathrm{y}} * \exp \left(-\mathrm{M}_{\mathrm{a}} / 2\right),
$$

where $\mathrm{a}=1,2,3$ and $\mathrm{y}=2000, \ldots 2015$ are indices of age and year, respectively, $\mathrm{N}$ is predicted abundance, NP is abundance projected with Pope's formula, C is catch and M is the instantaneous rate of natural mortality assumed in the assessment of the Iberian sardine stock, $M_{1}=-0.61, M_{2}=-0.47, M_{3}=-40$, which was obtained by multiplying by 0.7 the vector estimated with Gislason et al. (2010) formula (ICES, 2017b, 2017c).

Projected abundances represent the decrease of cohorts due to fishing mortality (derived from catches) and natural mortality (assumed), i.e. in the absence of inflow/outflow of fish. The model predicted abundances represent the combined effect of mortality and flow. Absolute flow indices between two given ages, FL in number of fish, were calculated for each cohort and area as:

$$
\mathrm{FL}_{\mathrm{a}}=\mathrm{N}_{\mathrm{a}+1}-\mathrm{Np}_{\mathrm{a}+1}, \text { for } \mathrm{a}=1,2,3,
$$

where a indicates the age at which the cohort moves into or out of the area. The flow was also calculated in relative terms, i.e. the number of fish that flow in or out of an area as a fraction of the number of individuals of the same cohort predicted to be in that area the following year:

$$
\mathrm{FLF}_{\mathrm{a}}=\mathrm{FL}_{\mathrm{a}} / \mathrm{N}_{\mathrm{a}+1}, \text { for } \mathrm{a}=1,2,3 .
$$

When there is inflow to (or outflow from) a given area, NP is lower (higher) than N, therefore, FL and FLF are positive (negative) (see Supplemental file Fig. S1).

To infer directional movement, age specific absolute flows were correlated between areas; given two inflow areas or two outflow areas, a positive correlation indicates synchrony and a negative correlation indicates asynchrony in fish movement; given two areas, an inflow 
and outflow area, a negative correlation suggests movement between the areas. A positive correlation may indicate the inflow area receives fish from another area that varies in opposite phase to the outflow area. A significance level of 0.007 was used to account for multiple comparisons (seven for each area) corresponding to the Bonferroni correction needed to maintain an alfa-familywise of 0.05 . Correlations significant at the $1.4 \%$ level (corresponding to an alfafamilywise of 0.1) were considered to be weakly significant.

Linear regression models were fitted to absolute flow indices to test relationships with recruitment (abundance-at-age 1 predicted by the GAM), environmental variables (winter SST, summer SST and fall Chl-a) and age (factor). Data for each of the areas were modelled separately because the range of covariate values did not overlap. Total abundance, mean fish density and the remaining environmental variables were not used in the models to avoid collinearity. Best fit models were selected by backward and forward elimination of variables based on the AIC. Residual plots were inspected to check normality, homoscedasticity and independence leading to the exclusion of a few outlying observations (0-9\% per area). All observations from 2009-2011 cohorts ( $\mathrm{N}=9$ ) were excluded from the NPOR model. A significance level of 0.05 was used to evaluate the effect of predictor variables.

Finally, the sensitivity of the flow fractions to alternative values of natural mortality and catchability-at-age of the acoustic surveys was evaluated. Two alternative M scenarios were tested with vectors obtained by multiplying the vector estimated with Gislason et al. (2010) formula by $0.6\left(\mathrm{M}_{1}=-0.52, \mathrm{M}_{2}=-0.40, \mathrm{M}_{3}=-34\right)$ and $0.8\left(\mathrm{M}_{1}=-0.70, \mathrm{M}_{2}=-0.53, \mathrm{M}_{3}=-46\right)$ (ICES, 2017b, 2017c). Two catchability-at-age (q) vectors were considered for each survey, the base case, assuming catchability equal to one, $\mathrm{q}=1$, at all ages (flat absolute catchability, scenario NONE) and an alternative case assuming an increase from age $1(\mathrm{q}=0.5)$ to ages $2+(\mathrm{q}=1)$ in the 
French and Spanish surveys (scenarios FR and SP, respectively) and a decrease from age 1 $(\mathrm{q}=1)$ to ages $2+(\mathrm{q}=0.5)$ in the Portuguese survey (scenario PT). Eight scenarios corresponding to combinations of the two cases and three surveys were tested: 1- NONE, 2: PT, 3: SP, 4: FR, 5: ES+PT, 6: FR+ES, 7: FR+PT, 8: ALL. For each scenario, survey abundance-at-age data were divided by the corresponding catchability-at-age factors to obtain the abundance-at-age of the population. A GAM with the same structure as the final model of the base case scenario was fit to each of the populations and flow fractions were calculated as described above.

\section{Results}

\subsection{Overview of sardine abundance, fishery and environmental conditions}

In the period 2000-2016, the total abundance of sardine in the study region varied from 7100 to 34,000 million individuals (mean $\pm \mathrm{SD}=16,700 \pm 7600$ million individuals). Mean abundance peaked in BISC and NPOR, was lower in SWPOR and southern Iberia and the lowest in northern Spanish waters (Fig. 2a). The pattern of mean density by area contrasted with that of abundance showing the lowest values in the BISC as a result of the large continental shelf area (Fig. 2b). Total biomass varied from 309 to 1304 thousand $\mathrm{t}$ (mean $\pm \mathrm{SD}=736 \pm 271$ thousand $\mathrm{t}$ ) and total catch up to 2015 varied from 49.5 thousand $t$ to 115.8 thousand $t$ per year (mean $\pm \mathrm{SD}=$ 99.4 19.4 thousand t), both varied by area similarly to abundance (Fig. 2c). Median harvest rates were lower in the BISC, CAN and CAD, intermediate in the Portuguese areas and higher in Galician areas (Fig. 2d). 
During winter and spring, mean water temperature increased with decreasing latitude, with the $\mathrm{BISC}$ (mean $\pm \mathrm{SD}=12.5 \pm 0.4^{\circ} \mathrm{C}$ ) being significantly colder than the $\mathrm{CAD}$ (mean $\pm \mathrm{SD}$ $16.7 \pm 0.4^{\circ} \mathrm{C}$ ) (Fig. 2e). During summer and fall, the areas in western Iberia were coldest $\left(<18.2^{\circ} \mathrm{C}\right)$, because of seasonal upwelling events, while the CAN $\left(\right.$ mean $\left.\pm \mathrm{SD}=18.7 \pm 1.2^{\circ} \mathrm{C}\right)$ and BISC (mean $\pm \mathrm{SD}=19.1 \pm 1.3^{\circ} \mathrm{C}$ ) had similar mean temperatures to the ones registered off southern Iberia (mean $\pm \mathrm{SD}=19.8 \pm 0.8^{\circ} \mathrm{C}$ ). Chl-a concentration was high all year round in SGAL (annual mean $\pm \mathrm{SD}=1.38 \pm 0.50 \mathrm{mg} \mathrm{m}^{-3}$ ) and NPOR (annual mean $\pm \mathrm{SD}=1.39 \pm 0.37 \mathrm{mg} \mathrm{m}^{-3}$ ), and during most of the year in the remaining Iberian areas, except for CAN, where Chl-a concentration was generally low (annual mean $\pm \mathrm{SD}=0.67 \pm 0.2 \mathrm{mg} \mathrm{m}^{-3}$ ) (Fig. 2f). The sardine density shows a positive relationship with Chl-a concentration in the summer/fall and tends to be higher in areas with medium-high temperatures in both winter/spring and summer/fall.

In the BISC, sardine abundance showed a slightly increasing trend from 2000 to 2016 (Fig. 3). Catches fluctuated around 13.6 thousand $t$ and increased sharply from 2012 onwards reaching 35-40 thousand $t$ in the latest years (Fig. 3). Off the northern Spanish areas and western Portuguese areas, there were marked, nearly concurrent variations of sardine abundance since the mid-1990s with abundance approximately doubling until the mid-2000s and decreasing thereafter to a level below that at the start of the period. In southern Iberia, sardine abundance showed a continuous decrease since 1997 with the most drastic change taking place in the CAD. Apart from the latter region, where catches fluctuated with no obvious tendency, catches decreased in all areas following an initial period of variability. Taking as a reference the period 2004-2008 when catches were at a high level, the decrease in mean catches up to 2013-2015 was 68.1\% in SWPOR, 72\% in NPOR and NGAL, and around 80\% in SGAL and CAN. Catches in SPOR started to decrease in the early 2000s and dropped 86.2\% from 1996-1999 to recent years. 
For all areas, mean winter and spring temperatures fluctuated during the period 19972016 (Fig. 3). In contrast, during summer, temperatures showed an increasing trend in Iberian areas apart from the CAN. A similar trend was seen during the fall, but only in the south of the Iberian Peninsula. In the BISC, exceptionally high temperatures occurred in the summer of 2003 $\left(22^{\circ} \mathrm{C}\right)$ and in the fall of $2016\left(21^{\circ} \mathrm{C}\right)$ while high variability was seen in other years. Chl-a concentration showed high interannual variability during the summer, winter and spring for all areas. During the fall, the Chl-a concentrations shifted from generally above the mean to below the mean in the early 2000s, a trend more noticeable in the BISC, CAN and southern Iberia.

\subsection{Spatial and temporal distribution of cohorts}

The selection of models fitted to sardine presence and count data is presented in Table 1. The two-way interactions of the final presence/absence model indicate that both the presence of ages and that of cohorts varied significantly between areas (Supplemental file FigS2). Smoothers within some of the areas were linear or approximately linear. All cohorts and age groups were observed in the BISC, CAN, and SPOR leading to predicted presence close to $100 \%$. Predicted presence was consistently high in the remaining areas, with medians of $98 \%$ (interquartile range (IQR) between $0.4 \%$ in SPOR and $10 \%$ in NPOR). The exceptions were NGAL where sardine presence was lower and more variable (median $\pm \mathrm{IQR}=72 \% \pm 40 \%$ ) and CAD where presence was high but varied substantially (median $\pm \mathrm{IQR}=97 \% \pm 23 \%$ ). Presence probability decreased with age, approximately linearly, in the western Iberian areas (SGAL, p=0.01; NPOR, $\mathrm{p}=0.03$, SWPOR, $p=0.03$ and CAD. $\mathrm{p}<0.001$ ) (Supplemental file Fig.S2, top panels). In NGAL presence showed a dome shape pattern with a maximum at ages $3-4$ years $(\mathrm{p}=0.07)$. Sardine presence did 
not vary significantly between cohorts in the BISC, CAN, South and SWPOR. In NGAL, presence was high for the 1999-2000 cohorts and dropped to a low level subsequently (around $60 \%$ in 2003-2015) (Supplemental file Fig. S2, bottom panels). In SGAL and NPOR, more sardines were present in the early and mid-2000s, respectively, and seem to show an increase in recent years (although confidence limits are large), whereas in the CAD it decreased sharply since 1999.

The final count model included all two-way interactions between area, age and cohort indicating that the sardine dynamics in the region is complex (Table 1, Supplemental file Fig. S3): cohort abundance varied between areas (cohort-area interaction), the rate of cohort decrease, integrating natural and fishing mortality and flow, varied across areas (significant areaage interaction) and age composition varied by cohort (age-cohort interaction). The model explained nearly $80 \%$ of the deviance. There are no signs of overfitting either from smoother plots or from the estimated number of degrees of freedom, which is around $11 \%$ of the total number of observations.

Sardine abundance-at-age by cohort in each of the areas predicted by the two-part GAM is shown in Fig.4. The age composition indicated predominantly younger fish except in northern Spanish areas, CAN and NGAL, where it was typically dome-shaped with a peak at ages 3-4 years, suggesting a movement of individuals into the areas (Fig.4). The 2000 and 2004 recruits were evident in both the BISC and off the western Iberian areas although they were 4-5 times more abundant in NPOR than in BISC. These cohorts were not evident in NGAL and the CAN at age 1 but instead became relatively abundant at ages 2 and 3. In 2008 and from 2012 onwards recruitment was high in the BISC and low in NPOR and the remaining western and southern Iberian areas. A weak signal of the 2012 cohort is seen in NGAL and the CAN (Fig. 4). 
However, none of the remaining strong cohorts recruited in BISC occurred in NGAL and the CAN with similar abundance to earlier strong cohorts recruited to the south.

In the BISC, recruitment had low interannual variations and a positive trend. In contrast, off the western Iberian areas, recruitment dropped to a low level following the strong 2000 and 2004 recruitments (Fig. 5). The geographical pattern of recruitment changed from 1999 - 2005 to 2006 -- 2015: in the earlier period various areas, the BISC, SWPOR and the CAD had moderate and strong recruitment and NPOR made the major recruitment contribution (57\%) in the entire study area (geometric mean $\mathrm{R}=6563$ millions of fish, $\mathrm{CV}=70 \%$ ); in the later period the BISC became the major recruitment area (geometric mean $\mathrm{R}=3076$ millions of fish, $\mathrm{CV}=51 \%$ ), representing $65 \%$ of the total while other areas represented each less than $15 \%$. During the low recruitment period, there were some relatively strong years in west and south Iberian areas, 2008-2009 and 2012-2013, respectively. The model predicts some improvement of year-class strength in recent years across the whole area. However, some caution is needed in the interpretation of these results since recent cohorts (since 2010) have fewer observations than earlier cohorts. Additionally, survey observations in Iberian areas became noisier in the recent period, when abundance decreased, leading to a poorer fit of the model (Supplemental file Fig. S4).

\subsection{Magnitude and directions of cohort flow}

Northern Spanish areas and SPOR were consistently inflow areas at all ages (1-3 years) and cohorts (Fig. 6). The BISC, western Portuguese areas and CAD were mostly outflow areas although shifts to inflow were seen at some ages. Flow fractions ranged from $-123.4 \%$ to 
$+118.5 \%$ showing high variability within and between areas (Table $2 \mathrm{a}$ ). The inflow was highest in NGAL (median $>90 \%$, all ages) with the number of fish entering the area at each age approximately equal to the number of local individuals. The CAN showed lower values (median $>35 \%$, all ages), followed by SGAL and SPOR (both median > 25\%, all ages). NPOR showed the highest fraction of outflow of all the areas, with more fish exiting the area than staying at age 1 (median $=-123.4 \%)$ but also the steepest decrease towards age 2 and eventually a shift to inflow at age 3 (Table 2a). Biscay and CAD had flow fractions generally lower than the other areas and opposite patterns with age which reflects temporal variations: in CAD there was a balanced at age 1 between incoming and outgoing fish while outflow predominated at ages 2 and 3 (median $<-26 \%$ ) whilst in Biscay there was a shift from inflow at age 1 to outflow at age 3. Movement tended to lessen over time in the Iberian areas leading, for example to shifts from outflow to inflow in western Portugal and CAD. This was not compensated by increased outgoing from the BISC (Fig. 6).

The number of local recruits and their survivors (i.e. not taking inflow into account) was lower than the number of individuals caught by the fishery the following year for more than $50 \%$ and $13 \%$ of the cohorts in NGAL and CAN, respectively, suggesting that local populations were not self-sustainable (Table 2b). Insufficient survivors at ages 2 and 3 were observed in SGAL and NPOR for up to 25\% of cohorts concurrent with unusually high inflow (Fig. 6). These outliers corresponded to data from the period 2009-2012 that showed poor cohort signals resulting in shallow slopes fitted by the model (Supplemental file Fig. S4). Finally, SPOR, despite being consistently an area of inflow appeared to have sufficient recruitment to sustain catches at ages 1 to 3 . 
Correlations between flow fractions at age 3 were not significant except for the pairs NGAL-SWPOR $(\rho=0.75, p<0.007)$ and NPOR-SPOR $(\rho=-0.74, p<0.007)$. Outflow from NPOR was significantly negatively correlated with inflow into the northern Spanish areas and into SPOR at ages 1 and 2 suggesting that cohorts moved both north and south as they grew older (Table 3). The BISC and the CAD appear to be partially isolated from the other regions and to have some synchrony with SWPOR suggested by weak positive correlations at ages 2 and 1 , respectively.

Flow fractions tended to increase, i.e. become generally more positive (either to support less outflow or to require more inflow) with an increase in natural mortality although the magnitude of change was generally smaller in areas where older fish predominated (northern Spanish areas) (Fig. 7). However, an increase or decrease of $M$ did not change the sign or temporal variability (the latter not shown) of flow fractions for most cohorts. The exceptions were at age 2 in Biscay and at age 1 in CAD where flows shifted from mostly outflow to mostly inflow as $\mathrm{M}$ increased.

Changes in the catchability-at-age of a given survey affected flow fractions mainly in the areas covered by that survey and the effects were comparable in all scenarios. In general, the impact was more pronounced than that observed for M scenarios. As was the case with M, changes in catchability had a minor influence on flow fractions in the northern Spanish areas. In the BISC, scenarios of lower survey catchability at age 1 relative to ages $2+$ resulted in lower flow fractions at age 1 and 2 compared to scenarios of absolute flat catchability (Fig. 8). Thus, both inflow at age 1 and the mixture of inflow/outflow at age 2 changed to mostly outflow whilst at age 3 the effects were minor. In the Portuguese areas, scenarios of higher catchability at age 1 relative to ages $2+$ lead to higher flow fractions at age 1 and lower at ages 2 and 3 . These effects 
did not imply major changes in the flow fractions in NPOR and SPOR, whereas SWPOR shifted to mostly an inflow area particularly at age 1 , and in CAD outflow increased at age 1 . Changing catchability-at-age had mainly a scaling effect on absolute flow rates, thus the patterns of correlations between areas were comparable between scenarios. The exception was the appearance of significant positive correlations at age 1 between SWPOR and CAD with northern Spanish areas and SPOR (but not BISC and NPOR) when the catchability of the Portuguese survey changed.

\subsection{Relationship between absolute flow, age, recruitment and environmental variables}

Final models were significant in all areas and explained more than $58 \%$ of the variability of absolute flow data apart from SGAL $\left(r^{2}=0.47, p<0.05\right)$ and SPOR $\left(r^{2}=0.21, p<0.05\right)$ (Table 3). Flow increased significantly with age off western Portugal, decreased significantly with age off BISC and CAN and was not significantly different between ages in the Galician areas and SPOR. The abundance of recruits had a significant effect on flow indices in models for all areas except for SPOR. The signal of the coefficient varied between regions: it was positive in the models for northern Spanish areas suggesting that inflow tended to increase with the increase of local recruitment, a counterintuitive effect; it was negative in BISC, western Portugal and CAD, suggesting that outflow tended to increase and inflow to decrease with increase of recruitment, an effect consistent with the hypothesis of density-dependent flow. Winter SST was retained in models for BISC and CAN with contrasting effects: higher winter SST was associated with higher inflow and lower outflow in BISC but to higher outflow in CAN. Chl-a in fall was significant in models for Galicia areas, SPOR and SWPOR and had a consistent positive effect 
meaning that the higher the Chl-a concentration the higher was the tendency of individuals to enter (higher inflow) or stay (lower outflow) in the area. Higher summer SST was associated with lower inflow NGAL and high inflow in SPOR.

\section{Discussion}

Two types of spatial population structure are frequently postulated for pelagic fish: discrete subpopulations and metapopulations (Goethel and Berger, 2017; Secor, 2015). Discrete subpopulations are reproductively isolated but mix outside the spawning season or area. Population structure is maintained by segregation of spawning grounds in space and/or time coupled with mechanisms of natal homing and larval retention. Natal homing has been detected in large pelagics such as tuna (Rooker et al., 2008) but also suggested for small pelagic fish such as the Pacific sardine (Sardinops sagax) in the California Current and the Japanese sardine (Sardinops melanostictus) in the Kuroshio current (Checkley et al., 2009). For sardine in Atlantic European waters there is no evidence of localized spawning areas, spawning site fidelity or seasonal migrations which may support the hypothesis of natal homing (Petitgas et al., 2010). The spawning area spreads almost continuously along the continental shelf from Britany to Gibraltar Strait (Bellier et al., 2007; Bernal et al., 2007). In the southern areas sardine spawns during six months, from late autumn to early spring; the season becomes shorter and shifts to spring towards the northern areas (Stratoudakis et al., 2007). Despite the existence of preferred and avoided spawning areas (Fig. 1), the spatial and temporal continuity indicates that interbreeding at adjacent areas is likely. On the other hand, persistent nursery and recruitment areas ("hotspots", Fig.1) are localized in a few inshore areas usually in the vicinity of high river 
discharge where both retention and productivity are high (Arístegui et al., 2009; Garrido et al., 2017; Santos et al., 2004).

The present study corroborated earlier indications (Silva et al., 2009) that cohorts recruited in the Bay of Biscay, western Portugal and the Gulf of Cadiz, which host sardine recruitment hotspots, flow out of their origin areas during pre-adult and adult life and supply adjacent areas such as northern Spanish waters and South Portugal where recruitment is insufficient to sustain local populations and fisheries. Such dynamics match with the source-sink hypothesis (Pulliam, 1988), defining source habitats as those that contribute an excess of individuals to the spawning stock to maintain populations in both source and in sink habitats; defining the latter as those which are unable to positively contribute to balance the losses by mortality. The spatial structure and dynamics of sardine observed in our study shows similarities to those reported for species such as horse mackerel in the Iberian coast (Murta et al., 2008) and common sole in the Eastern Channel (Archambault et al., 2016).

The North Portuguese waters acted as a source of sardine to the northern Spanish waters and to South Portugal, a result shown to be robust to changes in the assumed natural mortality rate and catchability-at-age in the surveys. Connectivity between sardine in the western and northern Iberian regions is in agreement with lack of genetic and persistent morphologic differences between sardines sampled in the two regions (Jemaa et al., 2015; Kasapidis et al., 2012; Silva, 2003). The higher mean length- and weight-at-age in the Northern Iberian areas and Bay of Biscay than in the western Iberian areas (ICES, 2016; Silva et al., 2008) may reflect northward migration of the larger individuals of each cohort (Secor, 2015). On the other hand, the latitudinal trend of length-at-age (and maturity-at-length; Silva et al., 2006) is consistent with the general rule that fish growing at higher temperatures (lower latitude) mature at a smaller size 
and therefore have lower growth than those growing at lower temperatures (van Rijn et al., 2017). If higher length-at-age results from local environmental conditions, individuals flowing from source areas may assimilate the biological characteristics of the sink populations, as reported in simulation studies of source-sink dynamics (Goethel and Berger, 2017).

The dispersion of sardine cohorts at age 1 from the Bay of Biscay to the eastern part of the Cantabrian Sea has some support from preliminary studies using area-based models and from indication of moderate year-class synchronicity between the two areas (ICES, 2006b; Silva et al., 2009). The results of our base-case analysis of flow are not consistent with a source-sink type of dynamics between these two areas instead, suggest low connectivity of Bay of Biscay with Iberian areas during the study period. Lower catchability-at-age 1 than at ages $2+$ in the French survey, as estimated in the assessment of the stock (ICES, 2017b) shifted the Bay of Biscay to mostly an outflow area but did not increase connectivity with the Cantabrian Sea, the neighbour sink area. The recent signals in the Cantabrian Sea and North Galicia of strong cohorts likely originated in the Bay of Biscay supports some mixing but did not point to massive inflow of cohorts as seen in the 2000s from western Portugal. The lack of strong connectivity is also obvious from the continued low abundance/biomass in the Cantabrian Sea despite recent strong recruitments in the Bay of Biscay. The low outflow from Biscay compared to North Portugal may be related to the lower population productivity (Jardim et al., 2018) and substantially lower density shown in the present study. The large continental shelf area and sufficient productivity to sustain sardine in Biscay may explain the lack of outflow despite the large abundance. Finally, it is unknown if mixing occurs between the Bay of Biscay and the English Channel populations; recent biological studies and data from the acoustic survey covering the latter area suggest that 
the southern Celtic Seas and the English Channel host a self-sustained sardine population (ICES, 2016).

The third hotspot of recruits of the Iberian Peninsula, eastern Gulf of Cadiz, was not significantly connected with South Portugal, the neighbour sink area, a result that was unexpected given the spatial continuity of the continental shelf and earlier evidence of some synchrony between year-class strength (Silva et al., 2009). A degree of separation of Cadiz from the western Iberian areas was also indicated by differences in morphometry (Jemaa et al., 2015; Silva, 2003) while some genetic (Kasapidis et al., 2012) and growth (Silva et al., 2008) studies pointed to affinity of Cadiz with the southwestern Mediterranean Sea. South Portugal showed some degree of connectivity with North Portugal in agreement with synchrony in year-class strength reported earlier between the two areas (Silva et al., 2009).

The magnitude of sardine flow was mainly driven by recruitment strength in agreement with a pattern of source-sink dynamics (Pulliam, 1988). Therefore, with the decrease of recruitment, both inflow and outflow decreased over time in the Iberian Peninsula areas. In most Iberian areas, lower outflow and higher inflow were also associated with higher food availability during fall, a period of fattening for sardine (Garrido et al., 2008; Nunes et al., 2011). As suggested by the geographic variability of summer and fall Chl-a, individuals moving from North Portugal to the south or to the north would encounter generally poorer feeding conditions, except in South Galicia where Chl-a concentrations are high all year round. Finally, decreasing winter temperature increased outflow/decreased inflow in the Bay of Biscay but showed an opposite effect in the Cantabrian Sea, suggesting that local temperatures could be close to the limits of tolerance for spawning and larval growth in the former area. Several lines of evidence from the laboratory and the field, such as the midpoint of the zone of thermal tolerance for the 
eggs, temperature tolerance limits for the larvae and the median temperature experienced in spawning areas, suggest that temperature for spawning and larvae growth is optimized in the 13$17^{\circ} \mathrm{C}$ interval (Garrido et al., 2016). Recent data suggest that recruitment strength at the Iberia seems to be favoured in this temperature range (Garrido et al., 2017).

The sardine population and fishery in the northern Spanish areas depends on the flow of sardine from western Portugal; in periods of low recruitment in the western recruitment regions, such as occurred in the late 1990s (Carrera and Porteiro, 2003) and has been occurring since 2006 (this study), the magnitude of the flow was not sufficient to sustain the populations along the Galicia and the Cantabrian Sea and a severe drop of abundance took place in those sink areas. In the late 1990s, signs of depletion were more severe in the northern Spanish areas than in the western Portuguese areas. However, the latter areas were subsequently highly affected with the new failure of recruitment and consequent loss of biomass that led to negative effects on local recruitment and supply to the northern Spanish areas. Our results showed that the sharp drop in sardine abundance in the northern Spanish areas was not avoided by inflow of sardine from the Bay of Biscay. Neither a rescue effect was noticeable on the western Iberian areas. South Portugal was also a sink area dependant on recruitment from the western areas but at the same time local recruitment appears to have been sufficient to sustain catches reported in the area.

For a full understanding of sardine spatial structure and population dynamics it is crucial to build knowledge on connectivity through all life stages. In the case of sardine, eggs and larvae are pelagic, therefore key stages in population connectivity. An early study of particle dispersal simulation by Oliveira and Stratoudakis (2008) pointed to low rates of mixing ( $<5 \%$ within one month) between adjacent shelf areas across a wide region from the Cantabrian Sea to South Morocco. This general pattern of low mixing was confirmed by two recent studies which also 
observed low but consistent alongshore transport which supports the idea of a sardine metapopulation. García-García et al. (2016), based on the 2007 cohort egg distribution, reported that $70-80 \%$ of simulated larvae were retained in the release area across the Iberian Peninsula and south Bay of Biscay; Santos et al. (2018) observed retention rates of 40-65\% for several scenarios of spawning distributions in space, depth and time in Iberian waters and adjacent Mediterranean and Moroccan areas. Both studies developed models which accounted for larval vertical migration and biological characteristics. Santos et al. (2018) reported substantial alongshore transport (up to $27 \%$ of simulated larvae) in the spawning season from North Portugal to Galicia and Cantabrian Sea, possibly associated with the Iberian Poleward Current. To the contrary, García-García et al. (2016) estimated less than 7\% transport on the northward direction, slightly higher rate southwards $(<15 \%)$ and some offshore transport. While the limited exchange across the northwest Iberian corner might be due to the existence of an oceanographic divergence zone acting as a barrier to connectivity (García-García et al., 2016) interannual variations are possibly high. Larvae moving south are likely to end in warm, highly productive areas, contrary to those moving north; therefore, larval transport from northern to western Iberia might contribute to close the loop of the predominant northward adult flow observed in our study.

Our results, combined with evidence on larval connectivity, support the current separation of the Bay of Biscay and Iberian Peninsula stocks for fisheries management; this separation is also in agreement with a recent study which addressed sardine population structure using stock assessment modelling (Jardim et al., 2018). From the South or Southwest Portugal to the Cantabrian Sea, there is substantial adult and larvae connectivity and similar population dynamics supporting the hypothesis of a self-sustained population. The major recruiting regions, 
mainly that of North Portugal and to a lesser extent Southwest Portugal, supply recruits to all remaining areas which are likely to mix and interbreed with locally recruited individuals. In the absence of natal-homing, the population appears to be split in source-juvenile and sink-adult subpopulations. The Gulf of Cadiz seems to have limited connectivity at the adult phase with the remaining Iberian areas, therefore this could be a third separate stock in the area although the boundaries are uncertain.

The complexity of sardine spatial structure and dynamics need to be further investigated, for example applying spatial analysis to the data of the acoustic survey, which might be complementary to our approach, and applying modern genetic analysis and otolith microchemistry. The exploration of area-based/metapopulation assessment models is desirable although not straightforward as existing practical examples are still very few and models are often data intense (Kerr et al., 2016). Accounting for source-sink connectivity between the western and northern Iberian is crucial to assist the recovery of the Iberian Peninsula stock; this may imply area-specific management plans, specific measures to protect recruitment in source areas and overall lower catch levels to reach MSY than if the whole area is managed as single self-sustained population (Goethel and Berger, 2017; Kerr et al., 2016). Assessment of the status of the Iberian Peninsula sardine can be distorted by the spatial uncoupling with the actual stocks dimensions. As such the reduction of sardine in recent years may appear sharper and more critic if analysed separately for two putative stocks, one distributed in the North and West Iberian waters and the other distributed in the Gulf of Cadiz.

Finally, the methodology used in the present study to derive flow indices is novel and might be useful to investigate movement in other stocks if relatively long and contrasting historical series of area-disaggregated data are available. Fractions of inflow and outflow from 
each area derived here might be used to build movement matrices and explore multi-area assessments (Goethel and Berger, 2017). On the other hand, flow indices are dependent on the assumptions about natural mortality and survey catchability-at-age, which in turn, are confounded (Punt et al., 2014). Although we performed sensitivity tests using sensible scenarios and the outcomes did not invalidate our main conclusions, other options such as the combination of the two effects should be investigated.

\section{Conclusions}

This study indicated that sardines distributed within the region from the northern Bay of Biscay to the eastern Gulf of Cadiz in the period 2000-2016 were connected by movement of adults. There were large differences between areas with respect to the magnitude of fish flow. Flow rates between three large areas, the Bay of Biscay, the northern Spanish and Portuguese waters and the Gulf of Cadiz, were relatively low. The existence of recruitment hotspots within each of the three areas supports the hypothesis that they host self-sustained weakly connected populations forming a metapopulation.

Connectivity was the strongest in the northern Spanish and Portuguese waters: one half of the sardines recruited in North Portugal and a quarter of those recruited in Southwest Portugal moved to northern Spanish waters and, in a less extent to South Portugal, sustaining local populations and fisheries.

Movement was mainly driven by recruitment strength in the source areas although lower outflow and higher inflow were also associated with locally high food availability during fall, the season of fattening for sardine. 


\section{Acknowledgements}

The collection of acoustic and fisheries data on sardine within Iberian waters and the French Bay of Biscay result from the work of several researchers and technicians in the past three decades. E. Soares, D. Morais, R. Milhazes, A.V. Silva and J. Barra (IPMA, Lisbon, Portugal), M. Bernal, C. Porteiro and E. Peleteiro (IEO,Vigo, Spain), J. Massé (IFREMER, Nantes, France), and P. Alvarez and I. Rico (AZTI, Pasaia, Spain) are some of the people to whom we are grateful, but many others are possibly missing from this list. We are grateful to Mari Myksvoll and to an anonymous reviewer for their comments and suggestions and to Laura Wise and José Loff for the help to prepare the figures. This study was developed within the framework ICES expert groups WGHANSA, WGACEGG and ICES workshops WKSAR 2016, WKPELA 2017. This work was supported by the European Union Data Collection Framework; Instituto Português do Mar e da Atmosfera (IPMA); Institut de Recherche Halieutique, (IFREMER); AZTI Technalia; Instituto Español de Oceanografia (IEO); ACRI. MARE was funded with project UID/MAR/04292/2013 of the Portuguese Foundation for Science and Technology (FCT).

\section{References}

Archambault, B., Le Pape, O., Baulier, L., Vermard, Y., Véron, M., Rivot, E., 2016. Adultmediated connectivity affects inferences on population dynamics and stock assessment of nursery-dependent fish populations. Fish. Res. 181, 198-213. doi:10.1016/j.fishres.2016.03.023 
Arístegui, J., Barton, E.D., Álvarez-Salgado, X.A., Santos, A.M.P., Figueiras, F.G., Kifani, S., Hernández-León, S., Mason, E., Machú, E., Demarcq, H., 2009. Sub-regional ecosystem variability in the Canary Current upwelling. Prog. Oceanogr. 83, 33-48. doi:10.1016/j.pocean.2009.07.031

Bellier, E., Planque, B., Petitgas, P., 2007. Historical fluctuations in spawning location of anchovy (Engraulis encrasicolus) and sardine (Sardina pilchardus) in the Bay of Biscay during 1967-73 and 2000-2004. Fish. Oceanogr. 16, 1-15. doi:10.1111/j.13652419.2006.00410.x

Bernal, M., Stratoudakis, Y., Coombs, S., Angelico, M.M., de Lanzós, A.L., Porteiro, C., Sagarminaga, Y., Santos, M., Uriarte, A., Cunha, E., Valdés, L., Borchers, D., 2007. Sardine spawning off the European Atlantic coast: Characterization of and spatio-temporal variability in spawning habitat. Prog. Oceanogr. 74, 210-227.

doi:10.1016/j.pocean.2007.04.018

Cadrin, S.X., Kerr, L.A., Mariani, S., 2014. Stock identification methods: applications in fishery science, 2nd ed, Stock Identification Methods. Elsevier B.V. doi:10.1016/B978-0-12$397003-9.00018-7$

Cadrin, S.X., Secor, D.H., 2009. Accounting for Spatial Population Structure in Stock Assessment: Past, Present, and Future. In: Beamish, R.J., Rotshild, B.J. (Eds.), The Future of Fisheries Science in North America. pp. 405-426.

Carrera, P., Porteiro, C., 2003. Stock dynamics of the Iberian sardine (Sardina pilchardus, W.) and its implication on the fishery off Galicia (NW Spain). Sci. Mar. 67, 245-258.

Casey, K., Brandon, T.B., Cornillon, P., Evans, R., 2010. The Past, Present, and Future of the AVHRR Pathfinder SST Program. In: Barale, V., Gower, J.F.R., Alberotanza, L. (Eds.), 
Oceanography from Space: Revisited. Springer, pp. 325-340. doi:10.1007/978-90-481$8681-5$

Checkley, D.M., Ayon, P., Baumgartner, T.R., Bernal, M., Coetzee, J.C., Emmett, R., 2009. Habitats, In: Climate Change and Small Pelagic Fish, pp. 12-44.

Frisk, M.G., Jordaan, A., Miller, T.J., 2014. Moving beyond the current paradigm in marine population connectivity: Are adults the missing link? Fish Fish. 15, 242-254. doi:10.1111/faf.12014

García-García, L.M., Ruiz-Villarreal, M., Bernal, M., 2016. A biophysical model for simulating early life stages of sardine in the Iberian Atlantic stock. Fish. Res. 173, 250-272. doi:10.1016/j.fishres.2015.10.002

Garrido, S., Ben-Hamadou, R., Oliveira, P.B., Cunha, M.E., Chícharo, M.A., Van Der Lingen, C.D., 2008. Diet and feeding intensity of sardine Sardina pilchardus: Correlation with satellite-derived chlorophyll data. Mar. Ecol. Prog. Ser. 354, 245-256. doi:10.3354/meps07201

Garrido, S., Cristóvão, A., Caldeira, C., Ben-Hamadou, R., Baylina, N., Batista, H., Saiz, E., Peck, M.A., Ré, P., Santos, A.M.P., 2016. Effect of temperature on the growth, survival, development and foraging behaviour of Sardina pilchardus larvae. Mar. Ecol. Prog. Ser. 559, 131-145. doi:10.3354/meps11881

Garrido, S., Silva, A., Marques, V., Figueiredo, I., Bryère, P., Mangin, A., Santos, A.M., 2017. Temperature and food-mediated variability of European Atlantic sardine populations. Prog. Oceanogr. 159, 267-275. doi: 10.1016/j.pocean.2017.10.006.

Garrido, S., Silva, A., Pastor, J., Dominguez, R., Silva, A. V, Santos, A.M., 2015. Trophic ecology of pelagic fish species off the Iberian coast: Diet overlap, cannibalism and 
intraguild predation. Mar. Ecol. Prog. Ser. doi:10.3354/meps11506

Gislason, H., Daan, N., Rice, J.C., Pope, J.G., 2010. Size, growth, temperature and the natural mortality of marine fish. Fish Fish. 11, 149-158. doi:10.1111/j.1467-2979.2009.00350.x

Goethel, D., Berger, A., 2017. Accounting for spatial complexities in the calculation of biological reference points: Effects of misdiagnosing population structure for stock Status Indicators. Can. J. Fish. Aquat. Sci. cjfas-2016-0290. doi:10.1139/cjfas-2016-0290

ICES, 1998. Report of the Planning Group for Pelagic Acoustic Surveys in ICES Subareas VIII and IX, ICES CM 1998:G:2, 17 pp.

ICES, 2006a. Report of the Working Group on Acoustic and Egg Surveys for Sardine and Anchovy in ICES Areas VIII and IX (WACEGG), ICES CM 2006/LRC:18, 169 pp.

ICES, 2006b. Report of the working group on assessment of the stocks of Sardine, Horse Mackerel and Anchovy.

ICES, 2016. Report of the Workshop on Atlantic Sardine (WKSAR), ICES CM 2016/ACOM:41, $355 \mathrm{pp}$.

ICES, 2017a. Report of the Benchmark Workshop on Pelagic Stocks (WKPELA), ICES CM.

ICES, 2017b. Report of the Working Group on Southern Horse Mackerel, Anchovy and Sardine (WGHANSA), ICES CM 2017/ACOM:17, 549 pp.

ICES, 2017c. Report of the Benchmark workshop on pleagic stocks (WKPELA), ICES CM 2017/ACOM:35, 284 pp.

Jardim, E., Eero, M., Silva, A., Ulrich, C., Pawlowski, L., Riveiro, I., Holmes, S.J., Ibaibarriaga, L., Alzorriz, N., Citores, L., Scott, F., Uriarte, A., Carrera, P., Duhamel, E., Mosqueira, I., 2018. Testing spatial heterogeneity with stock assessment models. doi:10.1371/journal.pone.0190791 
Jemaa, S., Bacha, M., Khalaf, G., Dessailly, D., Rabhi, K., Amara, R., 2015. What can otolith shape analysis tell us about population structure of the European sardine, Sardina pilchardus, from Atlantic and Mediterranean waters? J. Sea Res. 96, 11-17. doi:10.1016/j.seares.2014.11.002

Kasapidis, P., Silva, A., Zampicinini, G., Magoulas, A., 2012. Evidence for microsatellite hitchhiking selection in European sardine (Sardina pilchardus) and implications in inferring stock structure. Sci. Mar. doi:10.3989/scimar.03366.29B

Kerr, L.A., Campana, S.E., 2013. Chemical composition of fish hard parts as anatural marker of fish stocks. Stock Identif. Methods Appl. Fish. Sci. Second Ed. 205-234. doi:10.1016/B978-0-12-397003-9.00011-4

Kerr, L.A., Hintzen, N.T., Cadrin, S.X., Clausen, L.W., Dickey-Collas, M., Goethel, D.R., Hatfield, E.M.C., Kritzer, J.P., Nash, R.D.M., 2016. Lessons learned from practical approaches to reconcile mismatches between biological population structure and stock units of marine fish. ICES J. Mar. Sci. J. du Cons. fsw188. doi:10.1093/icesjms/fsw188

Kerr, L., Cadrin, S., Secor, D., 2010. Simulation modelling as a tool for examining the consequences of spatial struc- ture and connectivity on local and regional population dynamics. ICES J. Mar. Sci. 67, 1631-1639.

Kritzer, J.P., Sale, P.F., 2004. Metapopulation ecology in the sea:from Levins' model to marine ecology and fisheries science. Fish Fish. Fish Fish 5, 131-140. doi:Doi 10.1111/J.14672979.2004.00131.X

Limborg, M.T., Pedersen, J.S., Jakob, H.H., Tomkiewicz, J., Bekkevold, D., 2009. Genetic population structure of European sprat Sprattus sprattus: Differentiation across a steep environmental gradient in a small pelagic fish. Mar. Ecol. Prog. Ser. 379, 213-224. 
doi:10.3354/meps07889

Lipcius, R.N., Eggleston, D.B., Schreiber, S.J., Seitz, R.D., Shen, J., Sisson, M., Stockhausen, W.T., Wang, H. V, 2008. Importance of Metapopulation Connectivity to Restocking and Restoration of Marine Species. Rev. Fish. Sci. 16, 101-110. doi:10.1080/10641260701812574

MacKenzie, K., Abaunza, P., 2013. Parasites as Biological Tags, in: Stock Identification Methods: Applications in Fishery Science: Second Edition. pp. 185-203. doi:10.1016/B978-0-12-397003-9.00010-2

Marques, V., 2005. Campanhas Acústicas Portuguesas Dirigidas a Sardinha ( Sardina pilchardus , Walb .) ( 1984-2003 ). IPIMAR, Instituto Nacional de Investigação Agrária e das Pescas, Lisbon.

Massé, J., Sanchez, F., Delaunay, D., Robert, J.M., Petitgas, P., 2016. A partnership between science and industry for a monitoring of anchovy \& sardine in the Bay of Biscay: When fishermen are actors of science. Fish. Res. 178, 26-38. doi:10.1016/j.fishres.2015.11.018

Massé, J., Uriarte, A., Angélico, M.M., Carrera, P., 2017. Pelagic survey series for sardine and anchovy in ICES Subareas 8 and 9 (WGACEGG) - Towards an ecosystem approach., ICES Cooperative Research Report.

Mcquinn, I.H., 1997. Metapopulations and the Atlantic herring. Rev. Fish Biol. Fish. 7, 297-329. doi:10.1023/a:1018491828875

Murta, A.G., Abaunza, P., Cardador, F., Sánchez, F., 2008. Ontogenic migrations of horse mackerel along the Iberian coast. Fish. Res. 89, 186-195. doi:10.1016/j.fishres.2007.09.016

Nunes, C., Silva, A., Soares, E., Ganias, K., 2011. The Use of Hepatic and Somatic Indices and Histological Information to Characterize the Reproductive Dynamics of Atlantic Sardine 
Sardina pilchardus from the Portuguese Coast. Mar. Coast. Fish. doi:10.1080/19425120.2011.556911

Oliveira, P.B., Stratoudakis, Y., 2008. Satellite-derived conditions and advection patterns off Iberia and NW Africa: Potential implications to sardine recruitment dynamics and population structuring. Remote Sens. Environ. 112, 3376-3387. doi:10.1016/j.rse.2007.09.018

Peoples, B.K., Frimpong, E.A., 2012. A snapshot analysis of age distributions of fishes in urban and forested Virginia streams. Urban Ecosyst. 15, 927-937. doi:10.1007/s11252-012-02436

Petitgas, P., Uriarte, A., Nogueira, E., Massé, J., Cotano, U., 2010. Life-cycle spatial patterns of small pelagic fish in the Northeast Atlantic. ICES Coop. Res. Rep. 306, 40-44.

Pita, A., Casey, J., Hawkins, S.J., Villarreal, M.R., Gutiérrez, M.J., Cabral, H., Carocci, F., Abaunza, P., Pascual, S., Presa, P., 2016. Conceptual and practical advances in fish stock delineation. Fish. Res. 173, 185-193. doi:10.1016/j.fishres.2015.10.029

Pope, J.G., 1976. An Investigation of the Accuracy of Virtual Population Analysis Using Cohort Analysis. Res. Bull. Int. Comm. NW Atl. Fish. 9, 65-74.

Pulliam, H.R., 1988. Sources, sinks, and population regulation. Am. Nat. 132, 652-661. doi: $10.2307 / 2461927$

Punt, A.E., Hurtado-Ferro, F., Whitten, A.R., 2014. Model selection for selectivity in fisheries stock assessments. Fish. Res. 158, 124-134. doi:10.1016/j.fishres.2013.06.003

Rodríguez-Climent, S., Angélico, M.M., Marques, V., Oliveira, P., Wise, L., Silva, A., 2017. Essential habitat for sardine juveniles in Iberian waters. Sci. Mar. 81, 000-000. doi:http://dx.doi.org/10.3989/scimar.04554.07A 
Rooker, J.R., Secor, D.H., De Metrio, G., Schloesser, R., Block, B.A., Neilson, J.D., 2008. Natal Homing and Connectivity in Atlantic Bluefin Tuna Populations. Science (80-. ). 322, $742-$ 744. doi:10.1126/science. 1161473

Ruzzante, D.E., Mariani, S., Bekkevold, D., André, C., Mosegaard, H., Clausen, L.A.W., Dahlgren, T.G., Hutchinson, W.F., Hatfield, E.M.C., Torstensen, E., Brigham, J., Simmonds, E.J., Laikre, L., Larsson, L.C., Stet, R.J.M., Ryman, N., Carvalho, G.R., 2006. Biocomplexity in a highly migratory pelagic marine fish, Atlantic herring. Proc. Biol. Sci. 273, 1459-64. doi:10.1098/rspb.2005.3463

Santos, A.M.P., Nieblas, A.E., Verley, P., Teles-Machado, A., Bonhommeau, S., Lett, C., Garrido, S., Peliz, A., 2018. Sardine (Sardina pilchardus) larval dispersal in the Iberian upwelling system, using coupled biophysical techniques. Prog. Oceanogr. 162, 83-97. doi:10.1016/j.pocean.2018.02.011

Santos, A.M.P., Peliz, A., Dubert, J., Oliveira, P.B., Angélico, M.M., Ré, P., 2004. Impact of a winter upwelling event on the distribution and transport of sardine (Sardina pilchardus) eggs and larvae off western Iberia: A retention mechanism. Cont. Shelf Res. 24, 149-165. doi:10.1016/j.csr.2003.10.004

Schwarz, C.J., 2013. Estimation of Movement from Tagging Data, in: Stock Identification Methods: Applications in Fishery Science: Second Edition. pp. 429-446. doi:10.1016/B978-0-12-397003-9.00018-7

Secor, D.H., 2015. Migration Ecology of Marine Fishes, 1st ed. Johns Hopkins University Press, Baltimore.

Secor, D.H., Kerr, L.A., Cadrin, S.X., 2009. Connectivity effects on productivity, stability, and persistence in a herring metapopulation model. ICES J. Mar. Sci. 66, 1726-1732. 
doi:10.1093/icesjms/fsp154

Shepherd, T.D., Litvak, M.K., 2004. Density-dependent habitat selection and the ideal free distribution in marine fish spatial dynamics: Considerations and cautions. Fish Fish. 5, 141152. doi:10.1111/j.1467-2979.2004.00143.x

Silva, A., 2003. Morphometric variation among sardine (Sardina pilchardus) populations from the northeastern Atlantic and the western Mediterranean. ICES J. Mar. Sci. doi:10.1016/S1054-3139(03)00141-3

Silva, A., Carrera, P., Massé, J., Uriarte, A., Santos, M.B., Oliveira, P.B., Soares, E., Porteiro, C., Stratoudakis, Y., 2008. Geographic variability of sardine growth across the northeastern Atlantic and the Mediterranean Sea. Fish. Res. doi:10.1016/j.fishres.2007.09.011

Silva, A., Moreno, A., Riveiro, I., Santos, B., Pita, C., Rodrigues, J.G., Villasante, S., Pawlowski, L., Duhamel, E., 2015. Sardine fisheries: resource assessment and social and economic situation, European Parliament. doi:10.1017/CBO9781107415324.004

Silva, A., Santos, M.B., Caneco, B., Pestana, G., Porteiro, C., Carrera, P., Stratoudakis, Y., 2006. Temporal and geographic variability of sardine maturity at length in the northeastern Atlantic and the western Mediterranean. ICES J. Mar. Sci. doi:10.1016/j.icesjms.2006.01.005

Silva, A., Skagen, D.W., Uriarte, A., Massé, J., Santos, M.B., Marques, V., Carrera, P., Beillois, P., Pestana, G., Porteiro, C., Stratoudakis, Y., 2009. Geographic variability of sardine dynamics in the Iberian Biscay region. ICES J. Mar. Sci. 66, 495-508. doi:10.1093/icesjms/fsn225

Stratoudakis, Y., Coombs, S., De Lanzós, A.L., Halliday, N., Costas, G., Caneco, B., Franco, C., Conway, D., Santos, M.B., Silva, A., Bernal, M., 2007. Sardine (Sardina pilchardus) 
spawning seasonality in European waters of the northeast Atlantic. Mar. Biol. 152, 201212. doi:10.1007/s00227-007-0674-4

van Rijn, I., Buba, Y., DeLong, J., Kiflawi, M., Belmaker, J., 2017. Large but uneven reduction in fish size across species in relation to changing sea temperatures. Glob. Chang. Biol. 23, 3667-3674. doi:10.1111/gcb.13688

Vasconcelos, R.P., Eggleston, D.B., Pape, O. Le, Tulp, I., 2014. in Exploited Marine Species 71, 638-647.

Was, A., Gosling, E., McCrann, K., Mork, J., 2008. Evidence for population structuring of blue whiting (Micromesistius poutassou) in the Northeast Atlantic. ICES J. Mar. Sci. 65, 216225. doi:10.1093/icesjms/fsm 187

Winship, C., Mare, R., 2014. Regression Models with Ordinal Variables. Am. Sociol. Rev. 49, 512-525. doi:10.2307/2095465

Zuur, A.F., Ieno, E.N., Walker, N., Saveliev, A.A., Smith, G.M., 2009. Mixed effects models and extensions in ecology with R, Mixed effects models and extensions in ecology with R. doi:10.1007/978-0-387-87458-6 
Table 1. Summary of the two-part Generalized Additive Models fit to the abundance of sardine in 2000-2016 acoustic surveys. P - presence/absence models, C - count models; s - isotropic interaction, te - anisotropic interaction; edf - estimated degrees of freedom; AIC - Akaike Information Criterion; AUC - Area Under the Curve. Final model in boldface. N=751 for P models and $\mathrm{N}=696$ for $\mathrm{C}$ models.

\begin{tabular}{|c|c|c|c|c|c|}
\hline$\overline{\text { Model }}$ & Terms & $\begin{array}{r}\text { Total } \\
\text { edf }\end{array}$ & AIC & AUC & $\begin{array}{c}\text { Deviance } \\
\text { explained } \\
(\%)\end{array}$ \\
\hline P1 & $s($ area, age)+s(cohort, area) & 35.5 & 280 & 0.95 & - \\
\hline $\mathrm{P} 2$ & s(cohort, area) & 27.0 & 305 & 0.92 & - \\
\hline P3 & $\mathrm{s}($ area, age $)$ & 11.9 & 369 & 0.76 & - \\
\hline C1 & te(cohort,area,age) & 3.6 & 7573 & - & 82.3 \\
\hline C2 & $\begin{array}{l}\text { te(cohort,area)+te(area,age)+te(age,coh } \\
\text { ort) }\end{array}$ & 76.4 & 7572 & - & 78.8 \\
\hline C3 & te (cohort,area)+te(area,age) & 69.9 & 7594 & - & 77.7 \\
\hline C4 & te(area,age)+te(age,cohort) & 46.2 & 7782 & - & 69.9 \\
\hline C5 & te( cohort,area)+te(age,cohort) & 68.3 & 7720 & - & 73.7 \\
\hline
\end{tabular}

Table 2. (a) Median fraction of flow (\%) by area and age, and (b) \% of cohorts that the number of local survivors (i.e. not accounting for inflow) is lower than catches taken from those cohorts by area and age. Negative fractions: outflow, positive fractions: inflow.

(a)

\begin{tabular}{lrrr}
\hline & \multicolumn{3}{c}{ Age (years) } \\
\cline { 2 - 4 } Area & 1 & 2 & 3 \\
\hline BISC & 28.9 & 0.1 & -18.4 \\
CAN & 75.3 & 51.9 & 35.6
\end{tabular}




\begin{tabular}{lrrr} 
NGAL & 118.5 & 102.5 & 91.5 \\
SGAL & 55.6 & 30.0 & 25.3 \\
NPOR & -123.4 & -40.7 & 33.7 \\
SWPO & & & \\
R & -39.8 & -13.5 & 61.5 \\
SPOR & 33.2 & 26.8 & 39.7 \\
CAD & 1.5 & -25.9 & -21.5 \\
\hline
\end{tabular}

(b)

\begin{tabular}{lrrr}
\hline & \multicolumn{3}{c}{ Age (years) } \\
\cline { 2 - 4 } Area & 1 & 2 & 3 \\
\hline BISC & 0.0 & 0.0 & 0.0 \\
CAN & 12.5 & 43.8 & 18.8 \\
NGAL & 68.8 & 81.3 & 56.3 \\
SGAL & 0.0 & 25.0 & 18.8 \\
NPOR & 0.0 & 12.5 & 18.8 \\
SWPO & 0.0 & 0.0 & 0.0 \\
R & 0.0 & \\
SPOR & 0.0 & 0.0 & 0.0 \\
CAD & 0.0 & 6.3 & 0.0 \\
\hline
\end{tabular}

Table 3. Spearman rank correlations of the absolute flows for each pair of areas at age 1 in the upper diagonal and age 2 in the lower diagonal. Values in boldface and underlined are significant at the alfa-familywise of 0.05 or 0.1 , respectively.

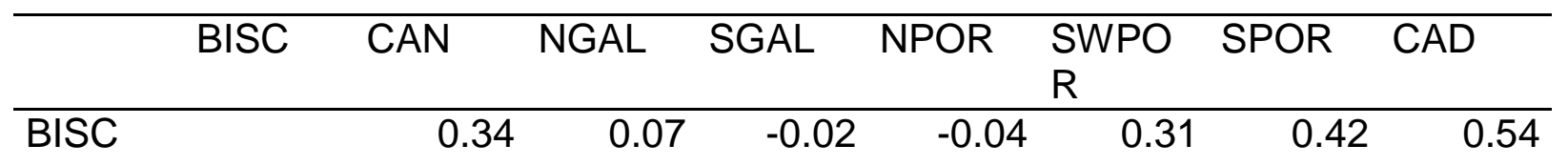




\begin{tabular}{lrrrrrrrr} 
CAN & -0.09 & & $\mathbf{0 . 8 9}$ & $\mathbf{0 . 6 6}$ & $\mathbf{- 0 . 8 9}$ & -0.31 & $\mathbf{0 . 7 6}$ & -0.29 \\
NGAL & -0.33 & 0.84 & & $\mathbf{0 . 7 6}$ & $\mathbf{- 0 . 8 9}$ & -0.31 & $\mathbf{0 . 7 1}$ & -0.20 \\
SGAL & 0.22 & 0.33 & 0.55 & & $-\mathbf{0 . 6 9}$ & -0.17 & 0.53 & -0.10 \\
NPOR & 0.13 & $-\mathbf{- 0 . 9 3}$ & $-\mathbf{0 . 8 5}$ & -0.28 & & 0.60 & $-\mathbf{0 . 6 5}$ & 0.52 \\
SWPO & $\mathbf{0 . 7 1}$ & 0.08 & -0.04 & 0.40 & 0.08 & & -0.20 & $\mathbf{0 . 7 9}$ \\
R & & & & & & & & 0.00 \\
SPOR & 0.42 & $\mathbf{0 . 8 1}$ & 0.65 & 0.39 & $-\mathbf{0 . 7 5}$ & 0.31 & & 0.00 \\
CAD & 0.49 & -0.39 & -0.53 & -0.12 & 0.57 & 0.62 & -0.06 & \\
\hline
\end{tabular}

Table 4. Linear regression models fit to the fractions of age 1 and age 2 individuals of each cohort that flow in to or out of each area.

\begin{tabular}{|c|c|c|c|c|c|c|c|}
\hline \multirow[t]{2}{*}{ Area } & \multicolumn{2}{|c|}{ Independent variables } & & $\bar{P}$ & \multicolumn{3}{|l|}{ Model } \\
\hline & Name & Coefficient & S.E. & $\mathrm{p}$-value & $r^{2}$ & Model p-value & D.F. \\
\hline \multirow[t]{5}{*}{ BISC } & Age 1 & -2240.0 & 941.8 & $2.3 \mathrm{E}-02$ & 0.67 & $2.53 \mathrm{E}-09$ & 37 \\
\hline & Age 2 & -500.9 & 72.6 & $3.8 \mathrm{E}-08$ & & & \\
\hline & Age 3 & -572.2 & 72.7 & 2.0E-09 & & & \\
\hline & $\operatorname{Rec}$ & -0.04 & 0.0 & $7.2 \mathrm{E}-02$ & & & \\
\hline & SSTw & 236.4 & 78.0 & $4.4 \mathrm{E}-03$ & & & \\
\hline \multirow[t]{5}{*}{ CAN } & Age 1 & 546.9 & 171.8 & $2.9 \mathrm{E}-03$ & 0.79 & $1.14 \mathrm{E}-12$ & 39 \\
\hline & Age 2 & -23.2 & 12.5 & 7.0E-02 & & & \\
\hline & Age 3 & -44.0 & 13.0 & 1.7E-03 & & & \\
\hline & Rec & 0.7 & 0.1 & 1.4E-12 & & & \\
\hline & SSTw & -39.3 & 13.1 & $4.6 \mathrm{E}-03$ & & & \\
\hline \multirow[t]{4}{*}{ NGAL } & Intercept & 99.5 & 52.3 & $6.5 \mathrm{E}-02$ & 0.79 & 1.14E-12 & 37 \\
\hline & Rec & 0.6 & 0.1 & 3.7E-09 & & & \\
\hline & SSTS & -7.5 & 2.7 & $8.1 \mathrm{E}-03$ & & & \\
\hline & Chlaf & 46.5 & 13.3 & 1.3E-03 & & & \\
\hline SGAL & Age 1 & -2.7 & 10.7 & 8.0E-01 & 0.47 & $6.59 \mathrm{E}-05$ & 38 \\
\hline
\end{tabular}




\begin{tabular}{rrrrrrrrr} 
& Age 2 & -20.4 & 6.0 & $1.6 \mathrm{E}-03$ & & & & \\
& Age 3 & -27.6 & 6.1 & $6.2 \mathrm{E}-05$ & & & \\
& Rec & 0.04 & 0.0 & $1.6 \mathrm{E}-02$ & & & \\
& Chlaf & 24.3 & 7.9 & $3.9 \mathrm{E}-03$ & & & \\
\hline NPOR & Age 1 & -1.1 & 0.1 & $4.1 \mathrm{E}-09$ & 0.74 & $1.94 \mathrm{E}-09$ & 32 \\
& Age 2 & 0.8 & 0.2 & $4.4 \mathrm{E}-05$ & & & \\
& Age 3 & 1.6 & 0.2 & $1.8 \mathrm{E}-10$ & & & \\
& Rec & $-4.3 \mathrm{E}-05$ & 0.0 & $5.6 \mathrm{E}-03$ & & & \\
\hline SWPO & Age 1 & -155.3 & 45.7 & $1.6 \mathrm{E}-03$ & 0.63 & $6.62 \mathrm{E}-08$ & 38 \\
R & Age 2 & 84.5 & 19.2 & $8.6 \mathrm{E}-05$ & & & \\
& Age 3 & 156.6 & 19.6 & $1.2 \mathrm{E}-09$ & & & \\
& Rec & $-1.4 \mathrm{E}-02$ & 0.0 & $1.3 \mathrm{E}-01$ & & & \\
& Chlaf & 87.9 & 53.9 & $1.1 \mathrm{E}-01$ & & & \\
& SPOR & Intercept & -243.4 & 98.9 & $1.8 \mathrm{E}-02$ & 0.21 & $9.38 \mathrm{E}-03$ & 40 \\
& SSTs & 12.3 & 4.6 & $1.1 \mathrm{E}-02$ & & & \\
& Chlaf & 38.5 & 12.2 & $2.9 \mathrm{E}-03$ & & & \\
\hline CAD & Intercept & 26.1 & 7.6 & $1.5 \mathrm{E}-03$ & 0.59 & $1.37 \mathrm{E}-09$ & 42 \\
& Rec & -0.1 & 0.0 & $1.4 \mathrm{E}-09$ & & & \\
\hline
\end{tabular}


Fig. 1. Map of the study region showing the area subdivision (solid lines) considered for acoustic estimation and reporting of catches: BISC - Bay of Biscay, CAN - Cantabrian Sea, NGAL North Galicia, SGAL - South Galicia, NPOR - North Portugal, SWPOR - Southwest Portugal, SPOR - South Portugal, CAD - Gulf of Cadiz. Thick black lines: stock boundaries, southern Celtic Seas-English Channel (CS) stock, Bay of Biscay (BoB) stock (ICES 8.a,b,d) and Iberian Peninsula stock (IP) (ICES 8.c and 9.a). The main ports for sardine catch sampling are indicated by black dots. Blue ellipses indicate recruitment "hotspots": Loire, Gironde and Adour river mouths in the Bay of Biscay (Massé et al., 2016; Petitgas et al., 2010), Northern Portuguese shelf centred off Aveiro, Southwest Portuguese shelf around Tagus estuary and the eastern Gulf of Cadiz (Marques, 2005; Rodríguez-Climent et al., 2017); rias in South Galicia are also areas of recruitment but their contribution appears to be small. The $200-\mathrm{m}$ isobath is shown. 


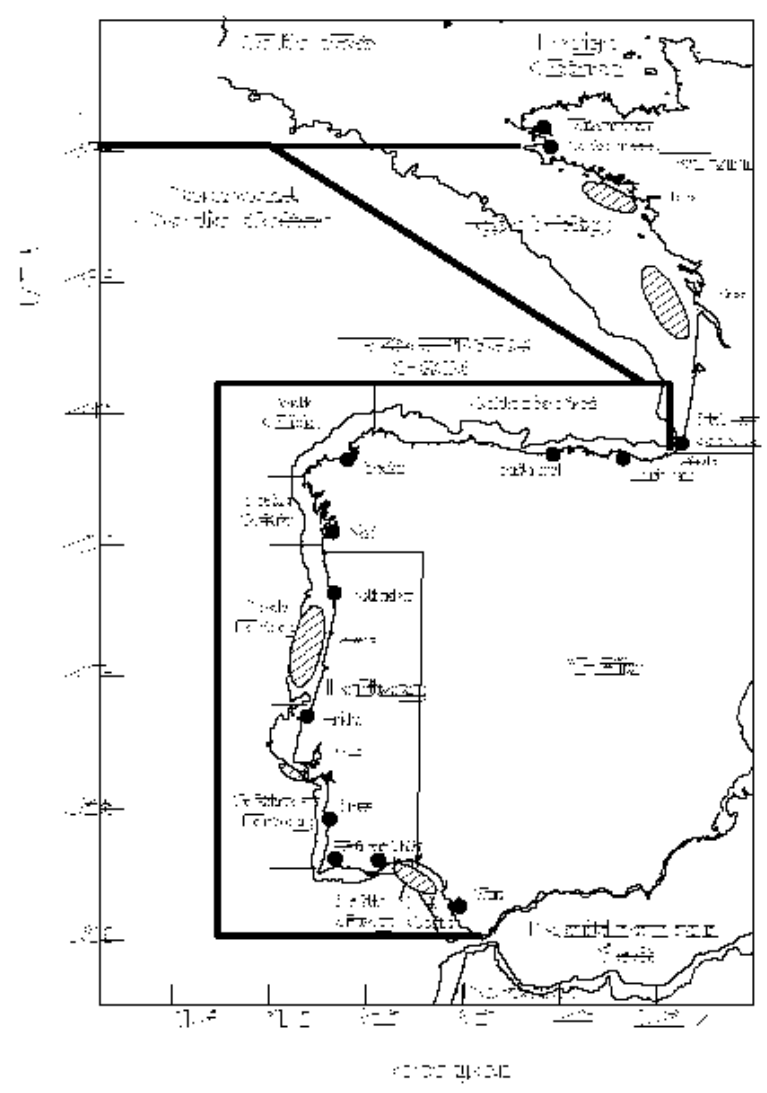


Fig. 2. Geographic variation of sardine a) abundance, b) density, c) catch, d) harvest rate, e) mean SST in winter (grey) and summer (white) and f) mean Chl-a in winter (grey) and fall (white). SST in spring and fall (not shown) have similar distributions to SST in winter and summer, Chl-a in spring and summer (not shown) have similar distributions to Chl-a in winter and fall. In panels a) to c) bars are mean values and segments 1 SD; in panel d) bars are median values and segments 1 inter-quartile range. Averages were calculated over the period 2000-2015 for catch and harvest rate and over the period 2000-2016 for the remaining variables. 


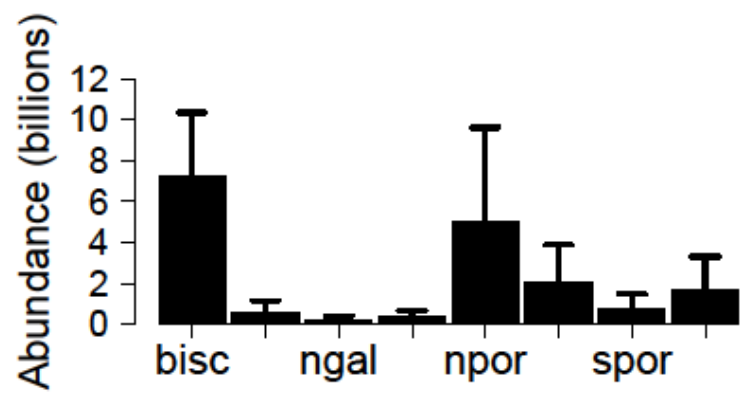




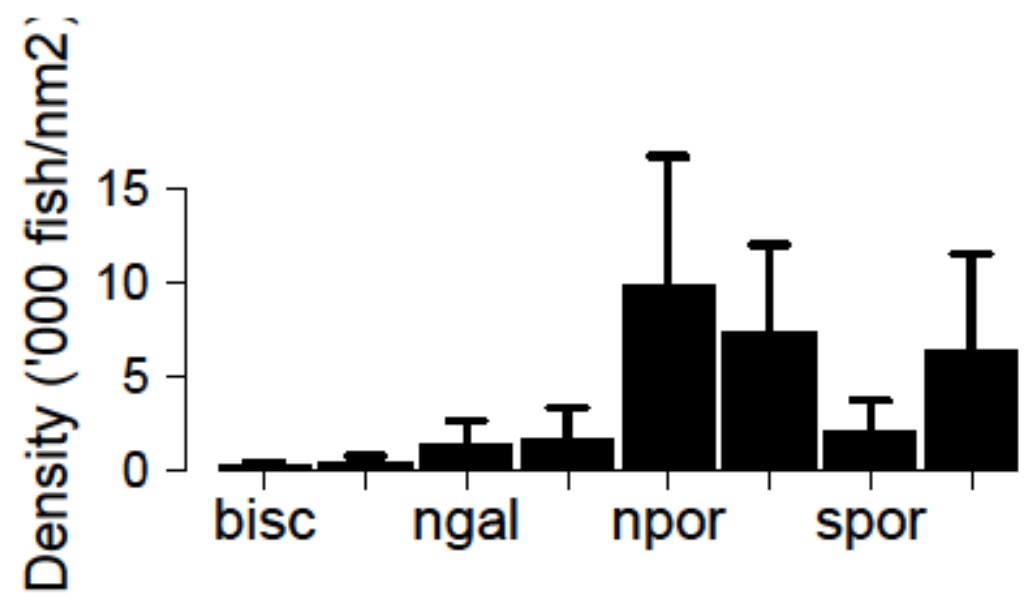




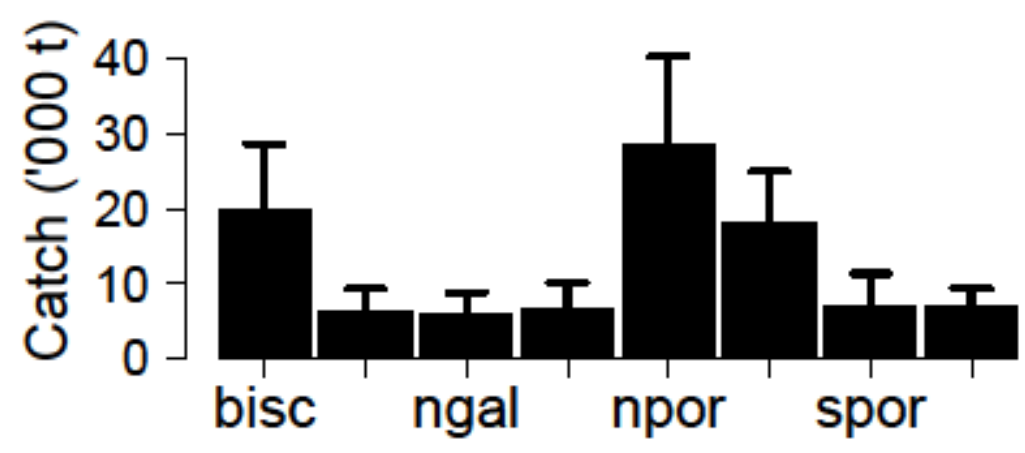




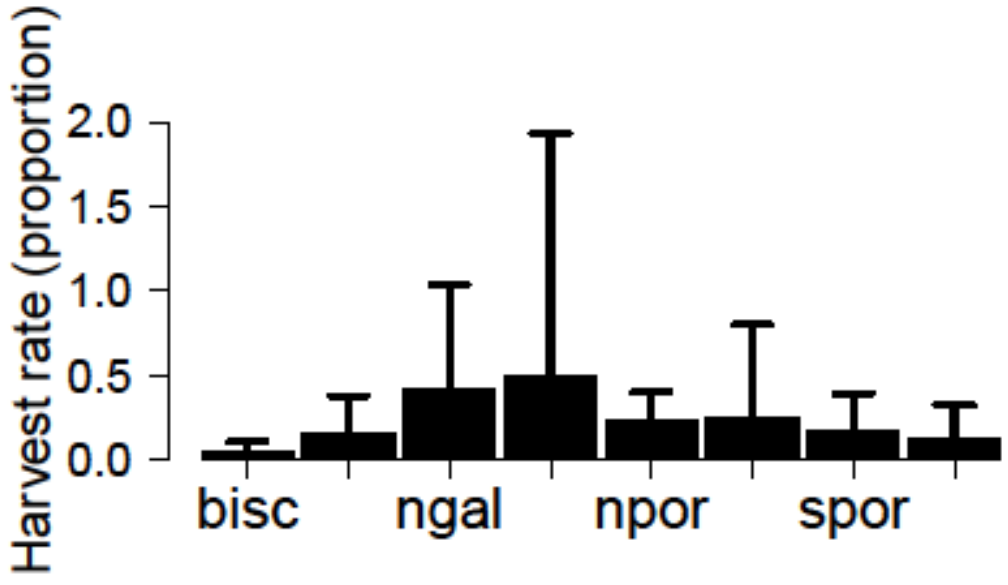




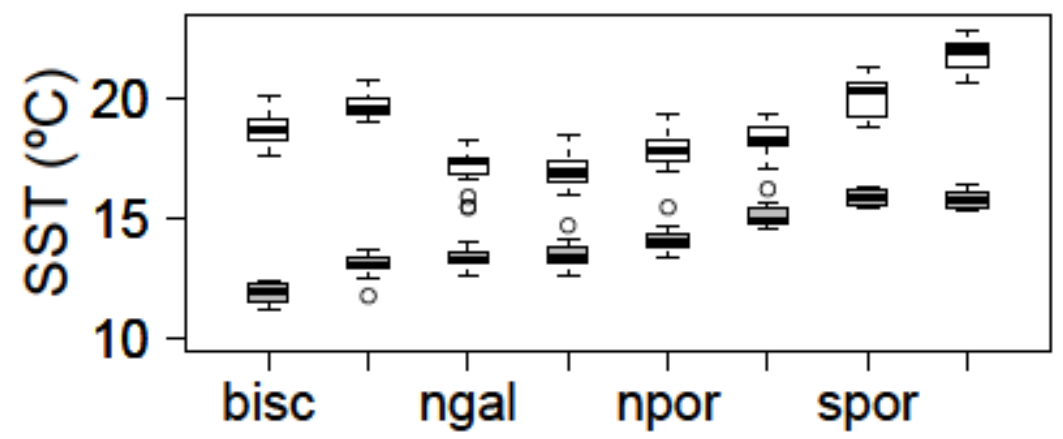




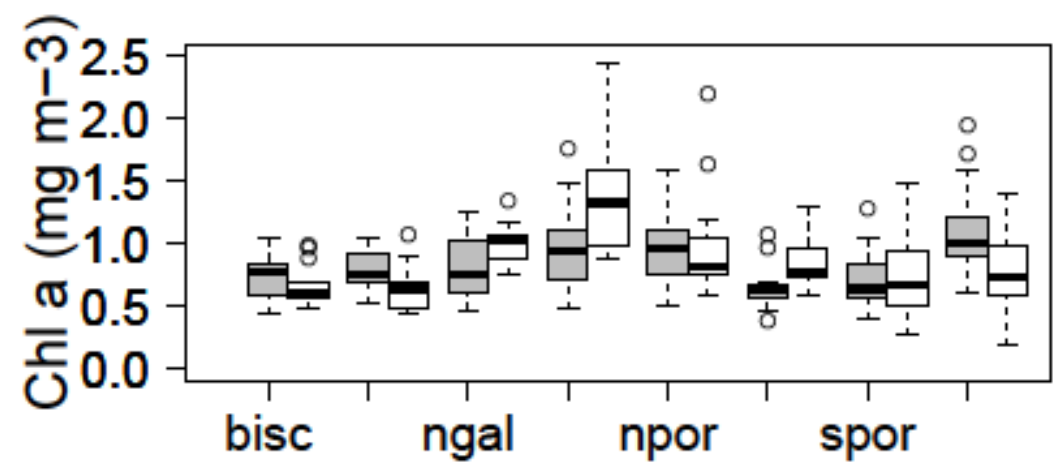


Fig. 3. Variation of sardine abundance, catch, SST and Chl-a in winter and fall in the period 1997-2016 by area. 


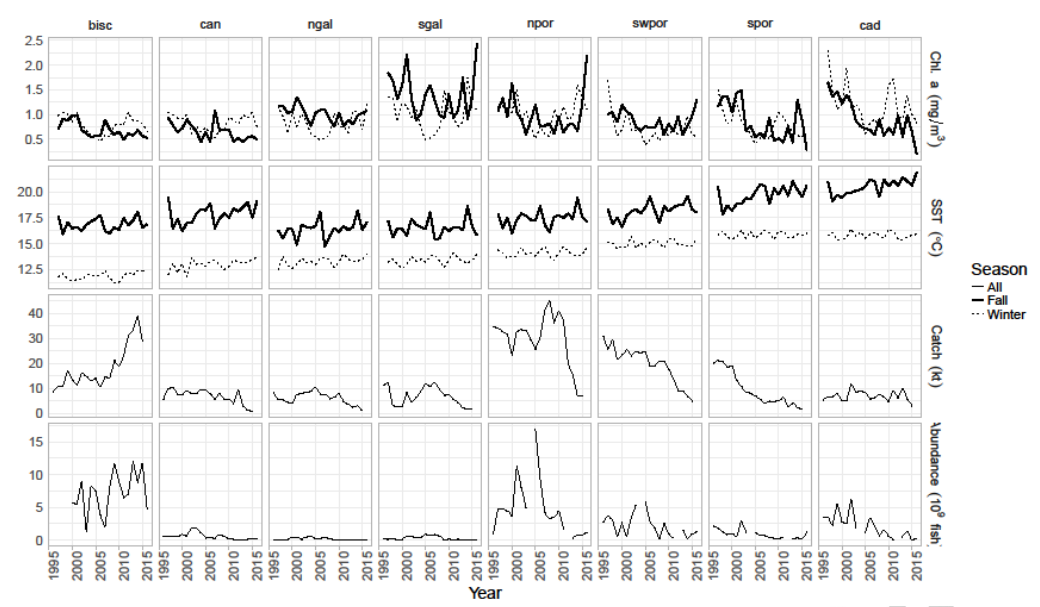


Fig. 4. Abundance, in log millions of individuals, of sardine 2000-2015 cohorts by age and area predicted by the two-part GAM model.

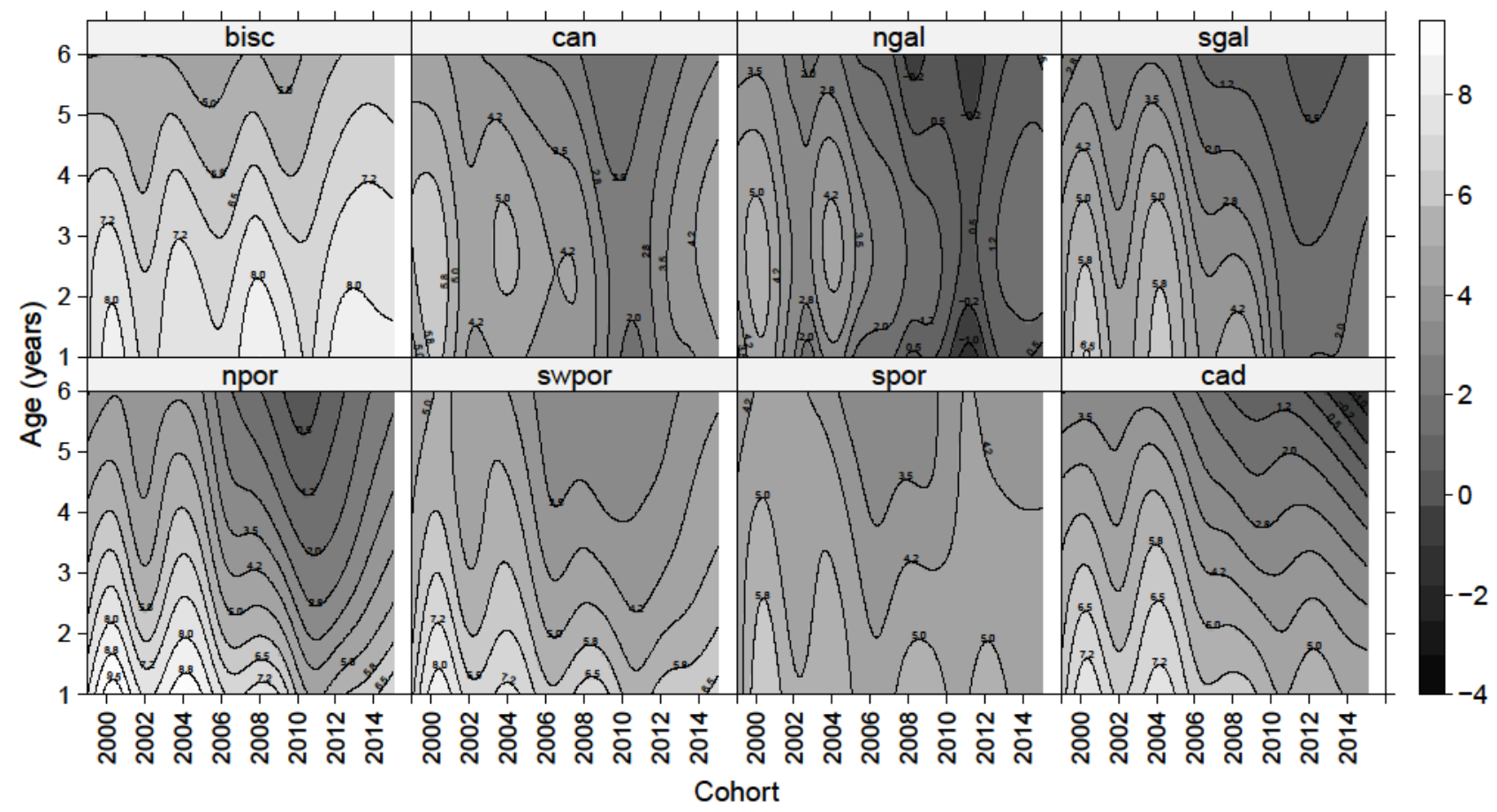


Fig. 5. Model predicted (dashed line) and observed (continuous line) abundance of recruits of the 1999-2015 cohorts in each area. Area between zero and the upper 95\% confidence interval is shaded. 

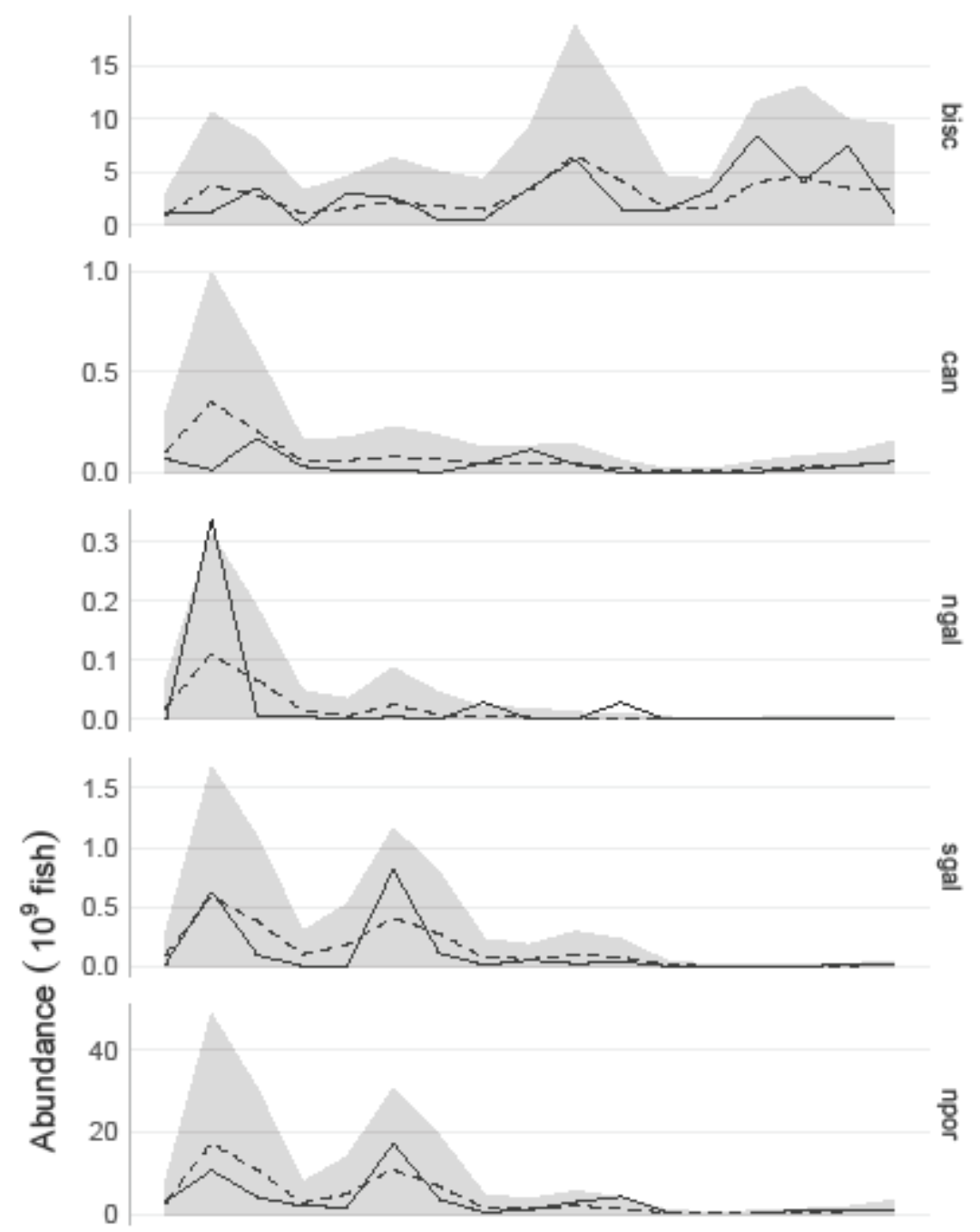

- Observed

- - Predicted
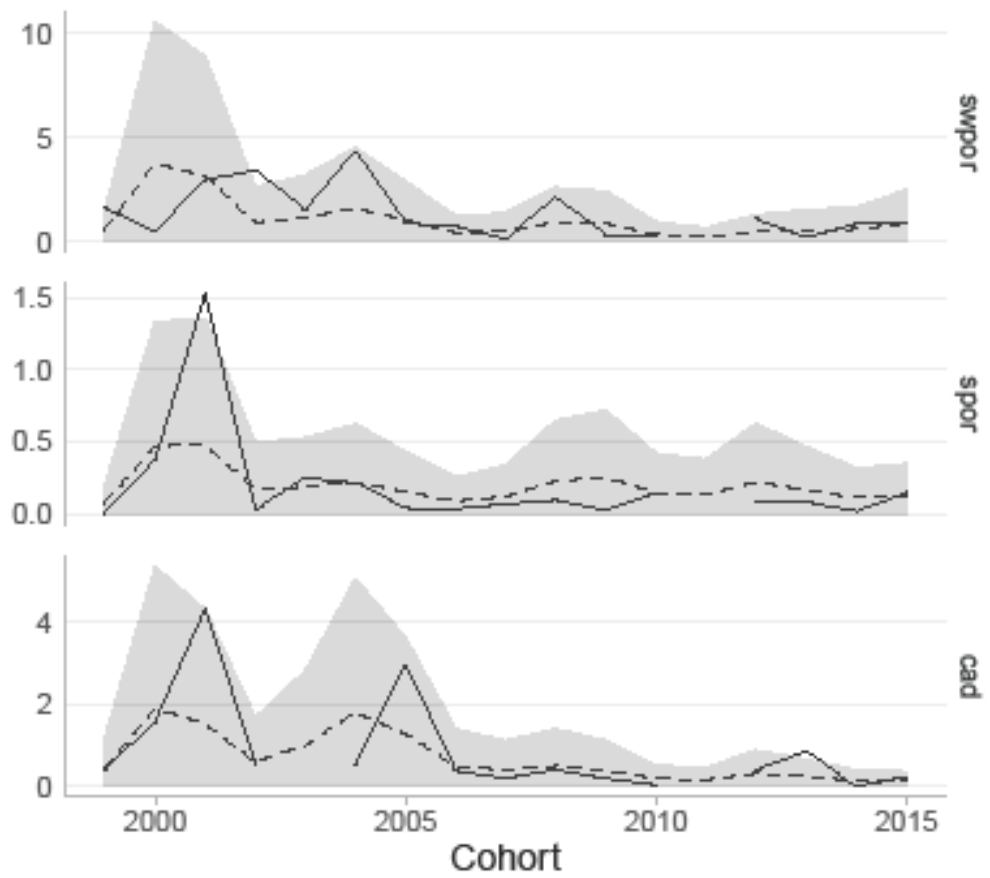
Fig. 6. Absolute flow index by cohort and area for ages 1-3 years. Positive values (blue palette) indicate inflow and negative values (red palette) indicate outflow. The breaks of the colour scale correspond to the quartiles of the positive and negative values. 


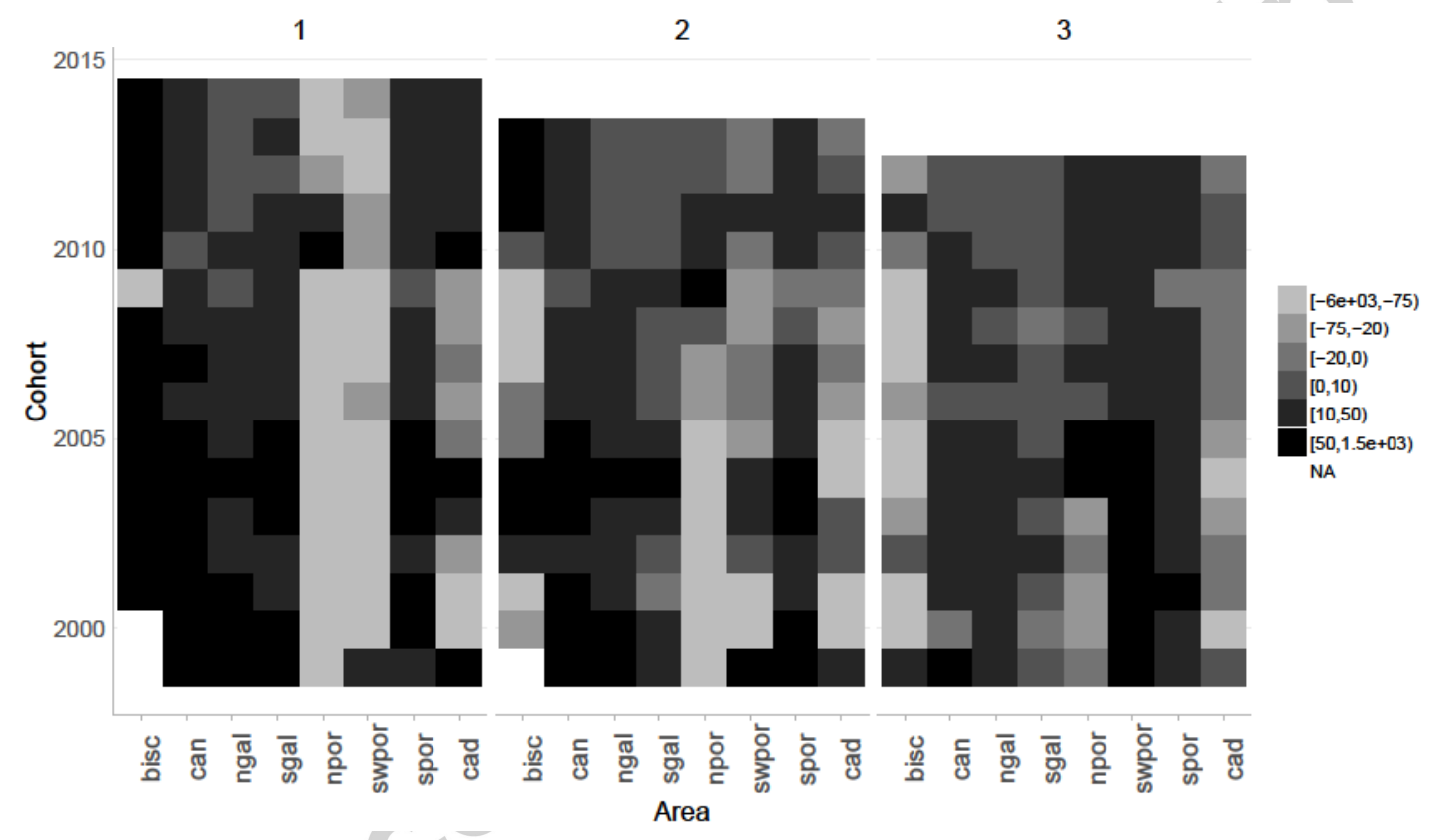


Fig. 7. Variation of the distributions of flow fractions by age and area with various natural mortality scenarios. A subset of the areas, BISC, NGAL, SGAL, NPOR, CAD, is shown as illustration. Scenario $\mathrm{M}$ factor $=0.6: \mathrm{M} 1=-0.52, \mathrm{M} 2=-0.40, \mathrm{M} 3=-34$, Scenario $\mathrm{M}$ factor $=0.7$ (base-case): $\mathrm{M} 1=-0.61, \mathrm{M} 2=-0.47, \mathrm{M} 3=-40$, Scenario $\mathrm{M}$ factor $=0.8: \mathrm{M} 1=-0.70, \mathrm{M} 2=-0.53$, $\mathrm{M} 3=-46$. 


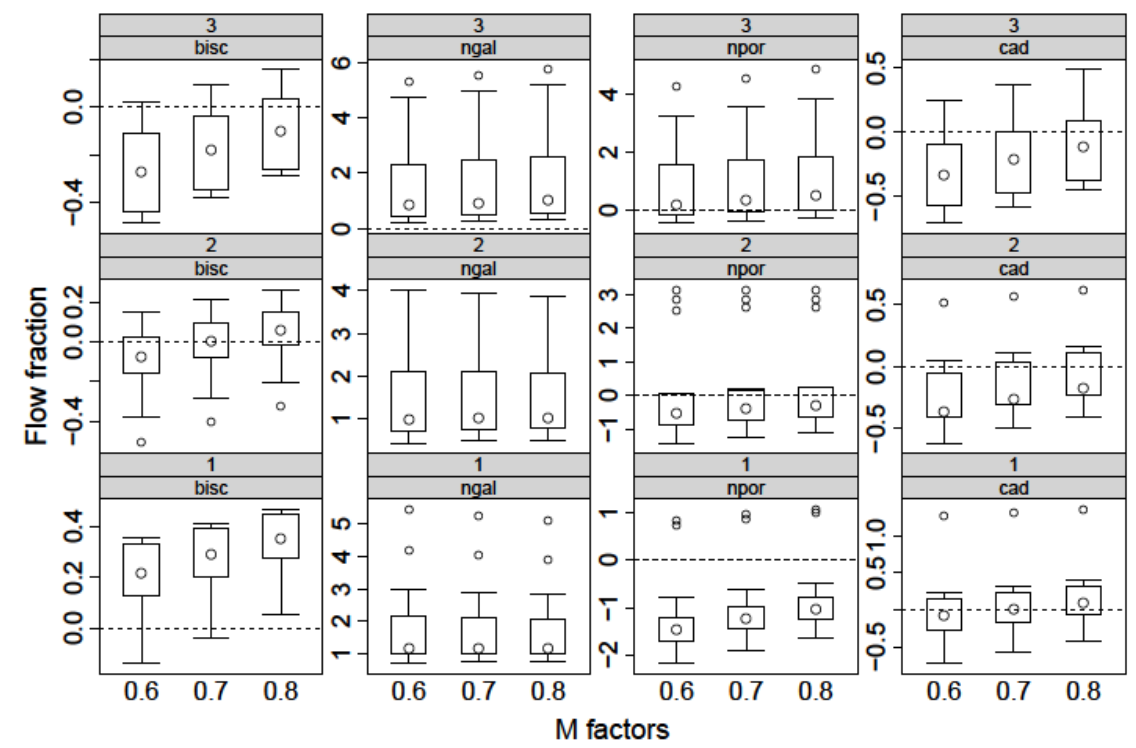


Fig. 8. Variation of the distributions of flow fractions by age and area with various catchabilityat-age scenarios. A subset of the areas, BISC, NGAL, SGAL, NPOR, CAD, is shown for illustration. Scenarios 1 to 8 correspond to combinations of two catchability-at-age vectors and three surveys: 1- NONE, 2: PT, 3: SP, 4: FR, 5: ES+PT, 6: FR+ES, 7: FR+PT, 8: ALL. There are two catchability-at-age (q) vectors for each survey, the base case, assuming catchability equal to one, $\mathrm{q}=1$, at all ages and an alternative case assuming, $\mathrm{q}$-a-age $1=0.5$ and q-at-ages $2+=1$ in the French and Spanish surveys (scenarios FR and SP, respectively) and q-at-age 1=1 and q-atages $2+=0.5$ in the Portuguese survey (scenario PT).

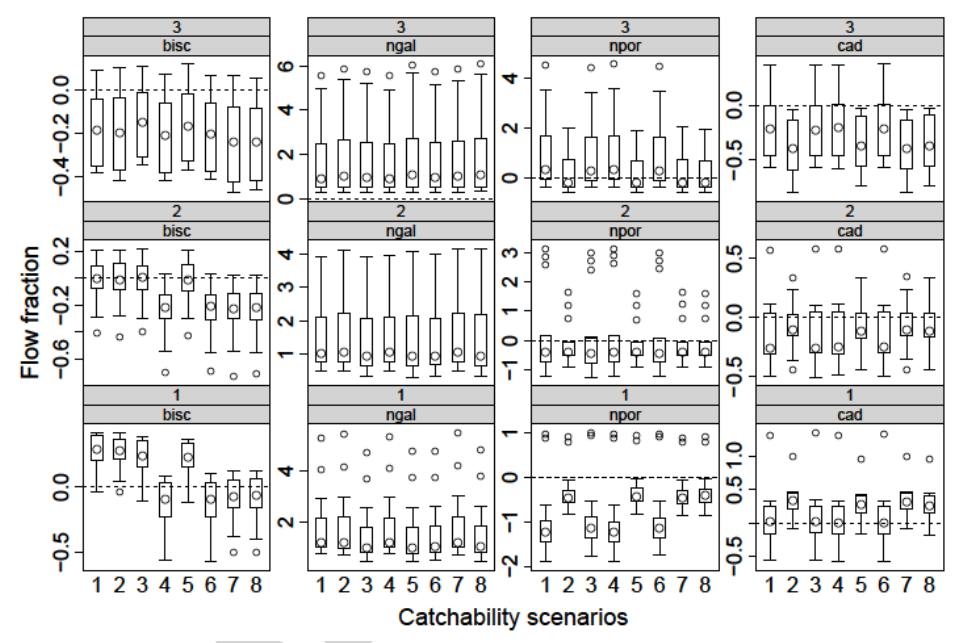

